\title{
Manuel Armijo Valenzuela
}

\author{
Francisco ARMIJO CASTRO ${ }^{(1-2)}$ \\ (1) Escuela Profesional de Hidrología Médica e Hidroterapia. Facultad de Medicina. \\ Universidad Complutense de Madrid. Plaza Ramón y Cajal s/n, 28040 Madrid (España). \\ (2) Departamento Medicina Física y Rehabilitación. Hidrología Médica. \\ Facultad de Medicina. Universidad Complutense de Madrid. Plaza Ramón y Cajal s/n, \\ 28040 Madrid (España). \\ farmijoc@med.ucm.es
}

\begin{abstract}
Resumen
Recogemos en este trabajo la biografía del profesor Manuel Armijo Valenzuela (19172012). Repasaremos su actividad como estudiante de Medicina, farmacólogo, y catedrático de esta disciplina en Cádiz y Valladolid; hidrólogo y catedrático de Hidrología Médica, en la Universidad Complutense, y académico de número de la Real de Academia Nacional de Medicina entre otros muchos méritos y cargos.

También hemos incluido algunos detalles de su vida más personales, su familia y su actividad profesional fuera de la universidad, para enmarcar mejor una trayectoria basada en el trabajo, las buenas maneras y el bien hacer.
\end{abstract}

Palabras clave: Manuel Armijo Valenzuela, Hidrología Médica, Farmacología, Sociedad Española Hidrología Médica

\section{Manuel Armijo Valenzuela}

\begin{abstract}
This paper puts together Professor Manuel Armijo Valenzuela's biography (1917-2012). It contains his activity starting when he was a medical student, a pharmacologist and later Professor of this subject in Cádiz and Valladolid; hydrologist and Professor of Medical Hydrology in the Complutense University and when he became a member of the Royal National Academy of Medicine amongst his many merits and occupations.

Some details of his personal life have also been included, like his family and his professional activity beyond the university so as to give e better picture of his life based on his career, his good manners and good will.
\end{abstract}

Key words: Manuel Armijo Valenzuela, Medical Hydrology, Pharmacology, Spanish Society of Medical Hydrology 
REFERENCIA NORMALIZADA

Armijo F. Manuel Armijo Valenzuela. Balnea, 2012, 7, 93-132.

\section{Nota previa}

Estaba previsto que esta breve biografía formara parte de la serie de monografías Balnea, la número siete, anexo de la revista Anales de Hidrología Médica que se publicaría para conmemorar el centenario de la Cátedra de Hidrología Medica Médica.

Desgraciadamente el día diez de abril nos llegó la noticia del fallecimiento de don Manuel Armijo que, por muy pocos días, no llegó a ver el centenario de su Cátedra. Inicialmente, ante esta situación, pensé en modificar el texto, que ya tenía escrito, acercándolo más a una nota necrológica, pero pensándolo bien lo he dejado integro, escrito como homenaje a quien aún vivía entonces, $\mathrm{y}$ al que profesaba un profundo respeto y cariño.

\section{INTRODUCCIÓN}

Cuando el profesor Francisco Maraver Eyzaguirre, mi amigo y compañero en las tareas de la Cátedra de Hidrología Medica de la Universidad Complutense de Madrid, me encargó la biografía de don Manuel Armijo Valenzuela, la propuesta no me hizo inicialmente muy feliz, pues conozco las dificultades que entraña este tipo de trabajo cuando existe una relación familiar entre el biografiado y el autor.

Las dificultades aludidas se deben a que el afecto, que debo y tengo hacia mi tío, puede distorsionar la realidad y a que, como ocurre en muchos de estos casos, aparezcan demasiado las vivencias del narrador. Procuraré no incurrir en ambos defectos, aunque en el caso del segundo, quizás sea éste mi único mérito para ser el autor de este trabajo.

El escritor aragonés Ramón de Lacadena y Brualla, bajo el seudónimo taurino de Don Indalecio, escribió en el prologo del libro de Francisco Mendoza dedicado al torero zaragozano Fermín Murillo y Paz: "Un zaragozano descollante, universitario, político y periodista, don Antonio Royo Villanova, dijo, los aragoneses nos contentamos con llegar a ser subsecretarios y novilleros. Y era verdad. Poco intrigantes, o poco ambiciosos, el aragonés no da codazos para llegar a la cúspide".

El mismo Ramón de Lacadena rebatía esta afirmación al mencionar a Fermín Murillo, torero de alternativa confirmada e ídolo en mi juventud y como político sólo basta recordar a Fernando II de Aragón y V de Castilla, más mentado como el Católico. En esta línea de aragoneses que han alcanzado lo más alto en su profesión incluyo a don Manuel Armijo Valenzuela, dos veces catedrático por oposición y académico numerario de la Real Academia Nacional de Medicina.

Siguiendo el símil taurino hay pocos diestros que dominan todas las suertes de la lidia, quien va bien de capa suele fallar con el estoque, Manuel Armijo Valenzuela dominó todas las suyas, catedrático, académico, farmacólogo, hidrólogo y médico de baños; además, fue un buen director de lidia y como tal lo veremos siendo direc- 
tor de una Sección del CSIC, Presidente del Consejo de administración de una empresa farmacéutica, director de un departamento de I+D y presidente de la Sociedad Española de Hidrología Médica.

\section{LA FAMILIA ARMIJO VALENZUELA}

Manuel Armijo Valenzuela nació en Zaragoza, el 30 de mayo de 1917 en la casa familiar situada en la calle Don Jaime I número 34, conocida como la casa de la Virgen del Rosario por una hornacina con una imagen de esta advocación que lucía en su fachada. En aquel enorme piso principal izquierda tenía su padre, el médico Baldomero Armijo García, su domicilio y su consulta, consistente en un despacho, una sala de exploración y dos salas de espera.

Don Baldomero era ginecólogo y en las jambas del portal de la casa existían dos placas blancas en las que bajo su nombre indicaba su especialidad; "Niños, Partos". Mi abuelo paterno de familia originaria de la pirenaica Jaca, era hombre de recio porte, según decían, genio vivo, y un gran trabajador, que repartía su tiempo entre su actividad como director del Hospital de la Cruz Roja, su consulta y la caza, a la que era un gran aficionado.

Su mujer, doña María Valenzuela La Rosa era de familia también aragonesa, pero de la rivera del Ebro, de Remolinos. Recuerdo a mi abuela como una mujer de de pequeña estatura pero de gran belleza, adornada con unos grandes ojos claros. Era hermana del ilustre abogado, escritor y académico José Valenzuela y aportaba a la familia la nota de armonía y tranquilidad.

El matrimonio tuvo dos hijos, Francisco, mi padre, nacido en 1912, que heredó

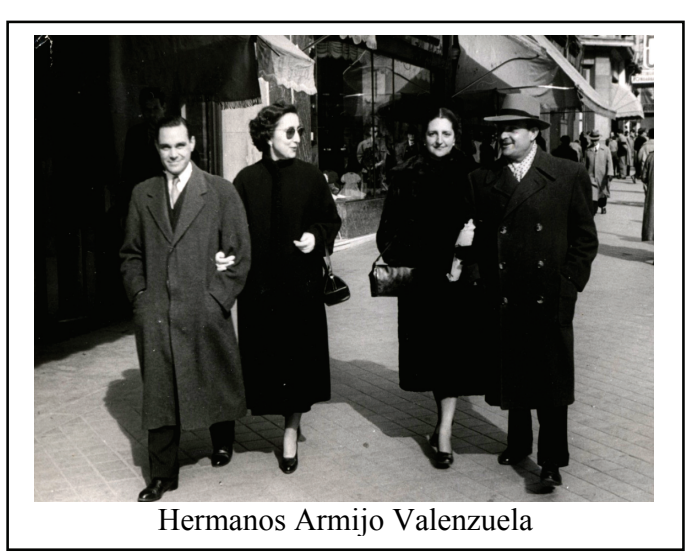
el porte y talante del suyo, y la profesión de su tío materno, y Manuel que mantiene el físico de su madre y la vocación de su padre. Esta combinación creo que dio muy buenos resultados y los hermanos, grandes trabajadores, se tuvieron siempre un gran cariño y respeto.

Sobre su vocación el mismo Manuel Armijo dijo en su memoria para optar a la cátedra de Hidrología: "Mi padre supo animarme en todas las ocasiones, siendo guía y encauzador de todas mis actividades, tanto más cuanto que habiendo dedicado toda su vida al ejercicio de la Medicina disponía de una experiencia de extraordinario valor".

Mis recuerdos más antiguos de Manuel Armijo Valenzuela se remontan a los primeros años cuarenta del siglo pasado, y son indirectos. Recuerdo unos grandes 
cestos de mimbre tapizados de tela azul llenos de libros, los de don Manuel que abandonaba la casa de mis padres en Madrid y de paso me dejaba su cuarto en herencia

\section{MANUEL ARMIJO VALENZUELA ESTUDIANTE}

Estudió el bachiller en el colegio de los Maristas de Zaragoza con muy buenas notas. Posteriormente cursó la Licenciatura de Medicina en la Universidad de Zaragoza. Si bien es verdad que estudió intensamente en su juventud, conozco que tuvo tiempo para la diversión y que hizo muy buenos amigos, que le gustaba jugar al futbol, llegando a ser interior derecha de la selección de su facultad y que continuó, al igual que otros catedráticos de esta universidad como mi profesor don Juan Cabrera y Felipe, siendo siempre del Real Zaragoza, aunque nuestro equipo no nos de muchas alegrías últimamente.

Durante la licenciatura de Medicina fue Alumno Interno Honorario de Anatomía el año 1934, de Microbiología en 1935 y Alumno Interno Pensionado por

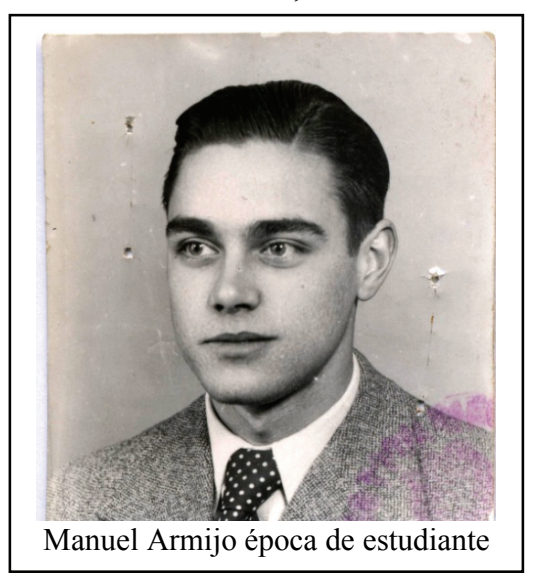
oposición de la sección de Clínicos en 1941

En el curso 1940-1941 terminó la carrera de Medicina y su expediente académico fue de los más brillantes con 18 Matrículas de Honor y premio Extraordinario de la Licenciatura. En el diario zaragozano Heraldo de Aragón se llegó a publicar esta noticia y no cabe duda que la buena formación adquirida, no sólo en las asignaturas propias de Medicina, sino también en otras, como la química, serían determinantes en su posterior labor profesional. La Universidad de Zaragoza tenía muy buenos profesores de química como Bruno Solano y Antonio de Gregorio

Rocasolano, y su trabajo se dejaba sentir no solo en los alumnos de esa licenciatura sino también en los de medicina.

\section{MANUEL ARMIJO VALENZUELA FARMACÓLOGO}

Parece ser que su vocación inicial fue la cirugía basándose en la buena formación que recibió en la asignatura de anatomía del profesor Gumersindo Sánchez Guisande y supongo que también en su extraordinaria habilidad manual. Ésta y su tesón le permitieron salvar y mantener sus dedos deformados por un accidente, que fueron la causa de que no pudiera seguir su opción inicial. 
Cuando obtuvo una plaza de alumno interno pensionada de Terapéutica Clínica, pasó a depender del profesor Benigno Lorenzo Velázquez, que, aunque hacía medicina del aparato digestivo, se dedicaba esencialmente a la farmacología, y esta situación le llevó al laboratorio y a ser farmacólogo, que no era en aquellos momentos su vocación.

El castellonense, afincado en Zaragoza, doctor Antonio Zubiri Vidal, en un artículo publicado en el Heraldo de Aragón del domingo 29 de Junio de 1986, recordaba sus tiempos de estudiante y describía la situación de la asignatura de Farmacología en 1935. "La explicaba el catedrático Benigno Lorenzo Velázquez, y lo de benigno es pura coincidencia, como señalan en las películas, por si muestran parecido con algunas personas o situaciones reales. Este catedrático es exigente al máximo y hay que conocer los fármacos con todo detalle".

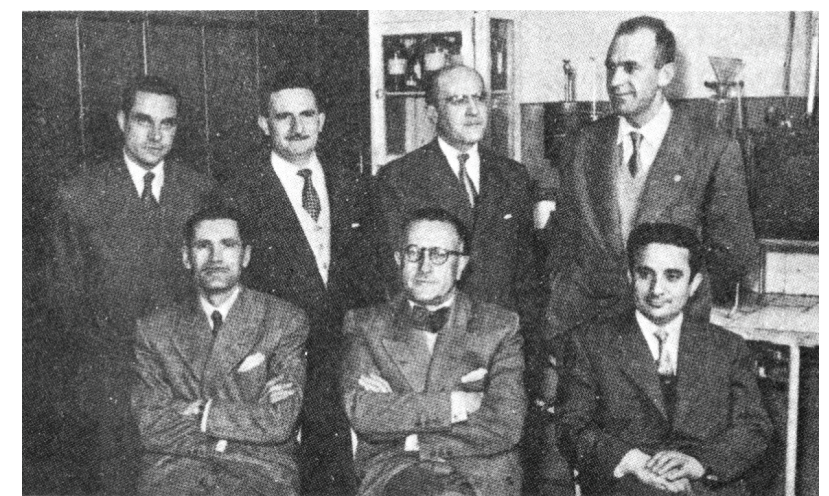

El profesor Velázquez, en 1944 con sus discípulos, profesores Armijo, García de Jalón, Bayo, y López Lorenzo, Mateo Tinao y Sanz Sánchez, formados en la Facultad de Zaragoza.

Cuando don Benigno Lorenzo se traslada a Madrid en 1941, a ocupar la cátedra de farmacología, por concurso de traslado, ofreció a Manuel Armijo la posibilidad de hacer la tesis doctoral con él, y así al terminar la carrera pasó a ser Preparador Técnico de la disciplina farmacológica en la Facultad de Madrid, en septiembre de 1941y enseguida profesor auxiliar de la misma desde 1942 a

1946.

Con la carrera recién terminada hizo oposiciones a Médico de la Cruz Roja, en Zaragoza, en la que obtuvo el número uno de las plazas que salieron a concurso en aquella ocasión.

Después de cursar como asignaturas de doctorado las de Análisis químico, Hidrología Médica, Electrología, y Radiología, en el año 1943 obtiene el doctorado con un trabajo titulado "Algunas acciones farmacológicas del salicilato sódico y sus relaciones con el shock peptónico e histamínico", obteniendo Premio Extraordinario en la sección de fundamentales.

El doctor Armijo Valenzuela explicaba posteriormente que en su tesis "trató de comprobar si esta sustancia [salicilato sódico] se podría comportar como protectora, según los trabajos de Fischer, Swift, Boots etc. hacian suponer. Nuestros resultados fueron precisamente los contrarios, ya que las dosis elevadas parecian sensibilizar a la acción de la peptona e histamina. Simultáneamente estudiamos la acción sobre la glucemia, calcemia, tiempo de sangría, fórmula hemática etc., 
comprobando el efecto hipoglucemiente al que muy posteriormente se le ha dado interés terapéutico, así como la acción hemorragipara que varios meses después Link y col comprobaron que era debido a efecto antiprotombínico. Ambas circunstancias evidenciaron la certeza de nuestras investigaciones".

Continuando con la información del afamado dermatólogo doctor Antonio Zubiri Vidal veamos que decía en el artículo antes citado: "El profesor Benigno Lorenzo Velázquez formó una escuela de farmacología en España y discípulo suyos y catedráticos fueron Mariano Mateo Tinao, Félix Sanz Sánchez, Manuel Armijo Valenzuela, Perfecto García de Jalón, Jose María Bayo Bayo, Pascual López Lorenzo y Francisco Javier Elio Membrado".

Otro ilustre médico zaragozano y presidente de su Academia de Medicina, el doctor Ricardo Horno Liria, dijo que: "realmente se trataba de una escuela de farmacología aragonesa, cuyos miembros se repartieron por toda la geografía española".

En 1944 Manuel Armijo Valenzuela oposita a una Cátedra de Farmacología, que

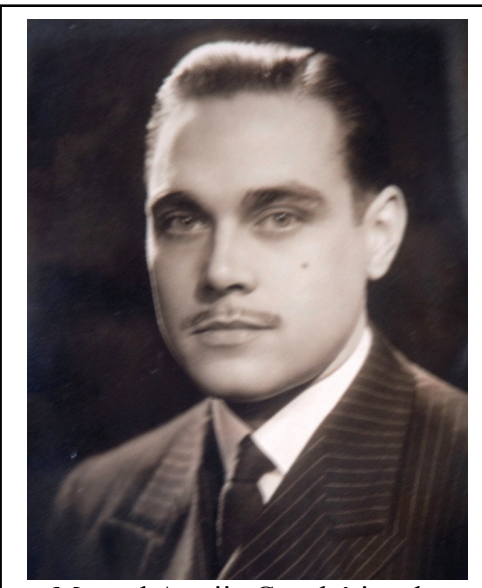

Manuel Armijo Catedrático de Farmacología el tribunal dejó desierta por considerarle excesivamente joven para obtener una cátedra de Medicina en cualquier universidad de España. Siempre he oído en mi casa que realizó unos brillantes ejercicios pero que su juventud, 27 años, y su falta de experiencia internacional, hicieron desistir al tribunal de adjudicársela.

Para eliminar estos obstáculos amplió sus estudios de farmacología pensionado por la Junta de Relaciones Culturales en el Laboratorio de la Facultad de medicina de Lisboa con el profesor Toscano Rico y sus colaboradores Gomez Da Costa y Mendez Alves, durante el curso 1945-46, $\mathrm{y}$ cursos de perfeccionamiento con el profesor Ficher en el Instituto Best de la Connaught Medical Research, de Toronto y en la Universidad de

Heidelberg y, en la de Berna con el profesor Wilbrandt; y por si acaso, se dejó un bigote con el que intentaba darle más edad a su rostro.

En la oposición celebrada en 1946 obtiene por unanimidad, la Cátedra de Farmacología de la Facultad de Medicina de Cádiz de la Universidad de Sevilla, de la que toma posesión en agosto de ese mismo año y en donde permanece hasta que pasa a la de Valladolid en 1949, cesando en esta en 1963.

En 1947 obtiene el Premio Doctor Garí de la Real Academia de Medicina de Zaragoza, creado por el doctor Francisco Garí y Boix, con un trabajo titulado "Reumatismos tributarios de la Terapéutica hidromineral en relación con los manantiales españoles", siendo nombrado Académico correspondiente de esta institución. 
Como farmacólogo fue el primer autor que señaló las interesantes acciones y uso profiláctico de las dosis masivas de vitamina $\mathrm{A}$, así como la acción del ácido salicílico sobre la coagulación sanguínea describiéndola en 1941 y confirmada posteriormente por Link, Oberman y colaboradores atribuida a la hipoprotombinemia.

La conocida Farmacología de Drill, en su cuarta edición, señalaba el hallazgo por primera vez publicado por el profesor Armijo Valenzuela en 1953 de las acciones espasmolíticas de la lobelina.

Fue Jefe de la Sección del Instituto de Farmacología de Valladolid del C.S.I.C desde 1948 a 1960.

Aunque como veremos, en 1963 obtuvo la Cátedra de Hidrología Médica, nunca abandonó su vocación de farmacólogo y en 1971 le encontramos interviniendo en

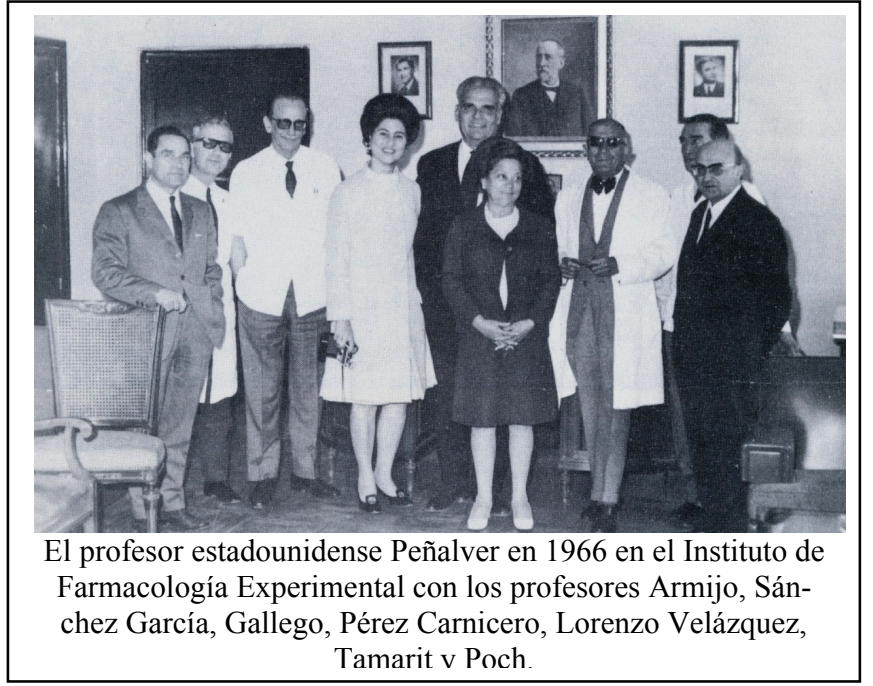

las sesiones de Trabajo durante la Inauguración de la Escuela Profesional de Farmacología y Terapéutica junto con los profesores Hernando, Sánchez Cuesta, Bayo y García de Jalón.

También fue director del Departamento de Investigación Básica de los Laboratorios ALTER, dónde su labor fructificó con la publicación de muchos trabajos investigación de esta rama de la medicina, hasta 1983.

Así mismo, durante muchos años fue primer editor de los Archivos de Farmacología y Toxicología, hasta 1986, fecha en que desapareció la Revista.

\section{MANUEL ARMIJO VALENZUELA HIDRÓLOGO}

El profesor de la Facultad de Medicina de Zaragoza don Ángel Abós, catedrático de Microbiología e Higiene y buen amigo de la familia Armijo, le indicó repetidas veces: "Que el complemento ideal de un catedrático era ser médico de baños. Pues esto permitía dedicarse en otoño e invierno a la cátedra y en verano a la atención del balneario".

El mismo Manuel Armijo decía: "Mis primeros contactos con la Hidrología comienzan en 1941 cuando inicié el estudio de esta asignatura en el Doctorado y, aunque sin polarizarme en este sentido, a partir de entonces le dedique una aten- 
ción preferente máxime cuando ya por entonces se aseguraba que en fecha próxima se celebrarían oposiciones a Médico Inspector del Estado en Establecimientos Balnearios".

En 1945 logra uno de los primeros números, el quinto, en las oposiciones citadas que no se celebraban desde 1905, en las que había obtenido plaza el maestro de su maestro; el profesor Teófilo Hernando. A estas oposiciones concurrieron muchos aspirantes notables, algunos catedráticos de universidad, Manuel Armijo todavía no lo era, y hay que destacar que el número uno lo obtuvo el también zaragozano doctor Valentín Pérez Argilés.

El tribunal lo presidió el eminente profesor Jiménez Díaz y, sorprendentemente, obtuvieron plaza muchos médicos que como él no había estado jamás en un balneario, ni tenían experiencia en Hidrología Médica. Fueron cincuenta y nueve los médicos que ganaron la oposición que ya posteriormente sólo se celebró en 1947.

Para ampliar estudios en esta disciplina realizó estudios de perfeccionamiento en Hidroterapia e Hidrología Médica en Clermont-Ferrant en los años 1962, 1964 y 1966 con los profesores Aublet Cuvelier y Courbaire de Marcillat.

Como médico de baños acudió a los establecimientos balnearios de Carballino durante cuatro años (1945 a 1949), a Fitero tres (1950 a 1952), a Puente Viesgo uno (1953), a La Toja uno (1955) y a Caldas de Oviedo dos (1961 y 1962).

En 1963 oposita a la Cátedra de Hidrología Médica de Madrid, vacante por el fallecimiento de José San Román y Rouyer en 1961, lográndola por unanimidad. En junio de 1963 se constituyo la Junta Asesora de Balnearios siendo nombrado vocal.

La Cátedra de Hidrología Médica de la Universidad Complutense, a partir de 1965, se ubica, inicialmente, en las instalaciones de la de Farmacología compartiendo unas mesas del laboratorio donde se instalaron algunos equipos para realizar los análisis de aguas, concretamente un $\mathrm{pH}$ metro Coleman, un Conductímetro Philips, un fotómetro de llama EEL y un colorímetro Doctor Lange, y el material de uso normal en el laboratorio.

En febrero de 1968 es nombrado director del Curso de Médicos Rehabilitadores de la Dirección General de Sanidad y de la Facultad de Medicina de Madrid.

Un hito importante en la labor del doctor Armijo Valenzuela fue la publicación en 1968 de su "Compendio de Hidrología Médica", en aquel momento el único libro actualizado en castellano de esta rama del conocimiento, que ayudó a formar a los doctorandos primero y luego a los alumnos de la Escuela Profesional de Hidrología durante más de veinte años.

En julio de 1969, con la inestimable colaboración del decano de la Facultad el profesor Benigno Lorenzo Velázquez, adquirió un Espectrofotómetro de Absorción Atómica con sistema de atomización de llama marca Perkin Elmer modelo 290 B que se instaló inicialmente en el laboratorio de Farmacología. Este equipo, de los primeros que se aplicaron en España, fue el origen de la gran labor analítica que desempeñó la Cátedra que contaba con un equipo de jóvenes profesores y doctorandos. 
En este mismo año 1969 la Real Academia Nacional de Medicina de Madrid le concedió el Premio Salgado por su labor en el campo de la Hidrología Médica.

Durante el curso1970-1971 se trasladó la Cátedra de Hidrología Médica desde su ubicación en la de Farmacología a su propio local en la $5^{\mathrm{a}}$ planta del Pabellón $5^{\circ}$. Las instalaciones de análisis pasaron de disponer de tres mesas, a cuatro laboratorios: dos de análisis instrumental, uno de química húmeda y otro de microbiología, tres despachos de profesores, una biblioteca y un aula.

Con el equipamiento analítico disponible Manuel Armijo Valenzuela consiguió un acuerdo con el INDIME, y la Cátedra, junto con otros laboratorios de referencia, realizó durante los años 1973 y 1974 el control de las aguas envasadas españolas, esta labor le llevó a disponer de trabajo para tres profesores y tres ayudantes de

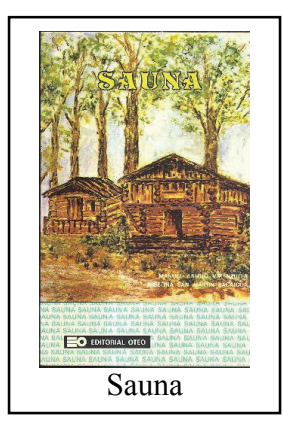
laboratorio y contribuyó al desarrollo de esta industria ya que se adaptaron a las modernas formas de expresión los análisis de muchas etiquetas que estaban ya obsoletas

En 1976 Manuel Armijo Valenzuela y Josefina San Martín Bacaicoa publicaron en Madrid, en la Editorial Oteo, el libro Sauna en dónde se reunió las experiencias sobre la aplicación de esta técnica termal.

Los profesores de la Cátedra Josefina San Martín y Francisco Armijo Castro obtuvieron una beca del CSIC en 1983 para realizar un trabajo consistente en el análisis de los manantiales y balnearios de la provincia de Teruel. Don Manuel Armijo colaboró activamente en la los trabajos de campo, participando en todos los desplazamientos para llevar a cabo las tomas de muestra a pie de manantial.

La ya citada buena formación básica en química y su asignatura de doctorado de Análisis Químico le permitieron hacer de la Cátedra una pionera en el uso de técnicas analíticas, no solo la espectrofotometría de Absorción Atómica ya citada, sino también los electrodos específicos, la cromatografía iónica y los texturímetros pasaron a formar parte de su parque de equipos, adquisiciones apoyadas y conseguidas por el profesor Armijo Valenzuela que sabía de las posibilidades del moder-

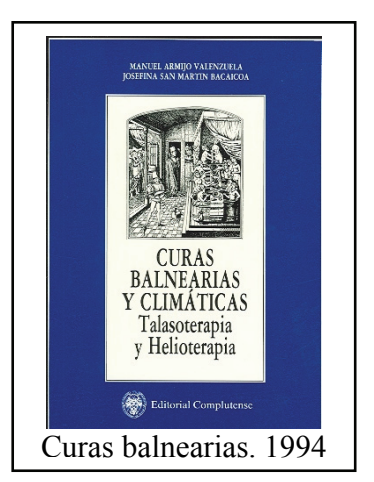
no análisis químico para conocer mejor las aplicaciones de las aguas mineromedicinales.

En 1984 Manuel Armijo Valenzuela y Josefina San Martín publican en la editorial EDAF el texto "La Salud por las aguas termales" y en 1994 en colaboración con la citada doctora Josefina San Martín y sus colaboradores Francisco Armijo Castro, Angeles Ceballos e Imelda San Martín las "Curas balnearias y climáticas", verdadera biblia de la Hidrología Médica española que todavía se sigue utilizando en la Escuela de Hidrología y que será difícil de sustituir en un período corto de tiempo. 
Siguiendo con la pauta de utilizar técnicas pioneras, en el año 1989 el equipo del laboratorio de análisis químico, realizó un análisis completo de un agua mineromedicinal por cromatografía iónica con supresión química, presentándose el trabajo en el XXXI Congreso mundial celebrado en Madrid en 1991, ya con la colaboración del profesor Francisco Maraver Eyzaguirre.

\section{DIRECTOR DE LA ESCUELA PROFESIONAL DE HIDROLOGÍA MÉDI- CA E HIDROTERAPIA}

El once de Mayo de 1978 es nombrado director de la Escuela Profesional de Hidrología Médica e Hidroterapia de la Facultad de Medicina de la Universidad Complutense, cuya primera promoción de alumnos se formó en el curso 1978/79

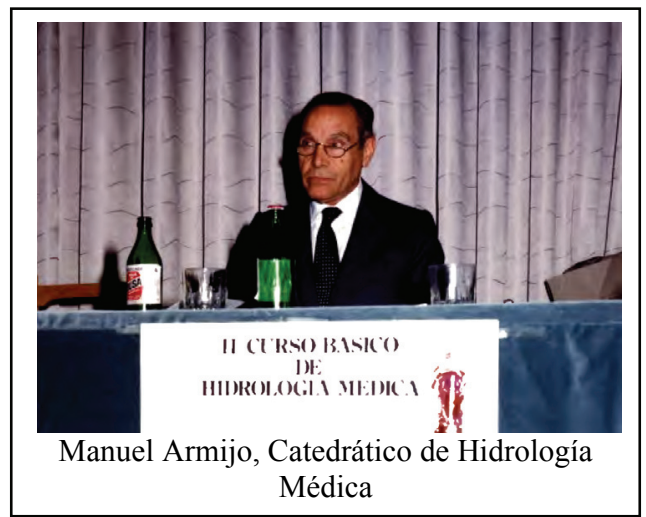

Posteriormente el Real Decreto 127/1984 reguló la formación médica especializada y la obtención del Título de Médico Especialista, en donde se incluía la Hidrología; el doctor Armijo Valenzuela permaneció como director de la Escuela hasta 1994 en que es sustituido por la doctora Josefina San Martín Bacaicoa y posteriormente en 2000 por el doctor Francisco Maraver Eyzaguirre.

También el mismo once de Mayo de 1978 fue nombrado director de la

Escuela Profesional de Reumatología. Como profesor de Farmacología y de Hidrología Medica ha dirigido 16 tesis doctorales que han alcanzado la calificación de "cum laude" y que detallamos a continuación con el título, el nombre del doctorando y la fecha de lectura.

- "Contribución al estudio de los compuestos antituberculosos". Tomás Hontoria Herrero. 1955

- "Influencia de los compuestos salicílicos y benzoicos sobre la actividad proteolítica de la pepsina". José Antonio Ferrández Portal. 1955.

- "Farmacología de los parasimpaticolíticos". Antonio Ledo Pozueta. 1955.

- "Aportación a la farmacología de los bloqueadores ganglionares". José María Wattenberg Sanpere. 1955

- "Contribución a la farmacología de los antiácidos". Luis Balmaseda Zabaleta. 1955. 
- "Contribución al conocimiento de la biología de la cornea, estudiada en cultivo de tejidos". Pedro Fernández de la Fuente, 1957.

- "Contribución al estudio de la estreptomicina y sus sales". Miguel Izquierdo San José. 1958.

- "Aportación a la farmacología de las tetraciclinas". Luis Pablo Rodríguez Rodríguez. 1965.

- "Estudio Experimental de la Neurotoxicidad de la sal sódica del ácido fusídico en comparación con la estreptomicina y su derivado" Carlos Roberto Goldbaum Brik. 1965.

- "Aportación a la farmacología del dimetilsulfóxido". Alfonso Velasco Martín. 1966.

- "Efectos de L-Glutamina, Piridoxal y Acido gamma Aminobutírico sobre glicolisis y respiración cerebral. José Miguel Arévalo Alonso.1970.

- "Efectos de la L-glutamina, Piridoxal y GABA sobre la glicolisis y respiración celular”. José Luis Velasco Martín. 1972.

- "Estudio experimental de la coenzima A sobre el tejido hepático". Jose Antonio Rodríguez Rodríguez.1973.

- "Relación entre la conductividad específica y densidad relativa de las aguas minero-medicinales y su residuo seco" Josefina San Martín Bacaicoa. 1975

- "Membranas artificiales. Su horizonte sanitario". Francisco Armijo Castro. 1989

_ “Aguas minerales Pirenaicas” José Luis Berdonces Serra. 1992

Ha sido Jefe del Departamento de Radiología y Fisioterapia de la Facultad de Medicina de la Universidad Complutense desde 1968 a 1972 y Profesor Emérito de la misma desde 1986 a 1994.

\section{PRESIDENTE DE LA SOCIEDAD ESPAÑOLA DE HIDROLOGÍA MÉ- DICA}

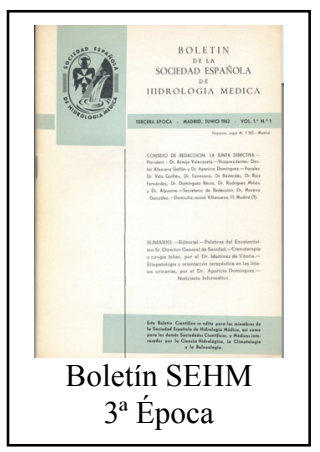

El 26 de febrero de 1877 tuvo lugar la Sesión inaugural de la Sociedad Española de Hidrología Medica, cuyo primer presidente fue el doctor José Salgado y Guillermo.

Casi un siglo después, en Junio de 1962 Manuel Armijo Valenzuela tomó posesión como presidente de la Sociedad siendo el promotor del Boletín de la Sociedad Española de Hidrología Médica que se publicó hasta 1964 fecha en que se interrumpió la publicación de la revista.

En su primera Editorial Manuel Armijo decía: "Reemprendemos la edición de este Boletín, en la seguridad de que este 
órgano es prácticamente indispensable para la buena marcha y prestigio de la Sociedad Española de Hidrología Médica. Nuestro Boletín debe ser la llamada, repetida con la mayor frecuencia posible, que nos haga pensar en nuestros problemas, al tiempo que nos estimule a mejorar y superar nuestra actividad en el campo hidrológico".

Después de las presidencias de Tomás Alcober en 1965 y Antonio Salces Blesa en 1969, en marzo de 1985, Manuel Armijo accede a por segunda vez a la presidencia de la Sociedad Española de Hidrología Médica y en enero de 1986 comienza la

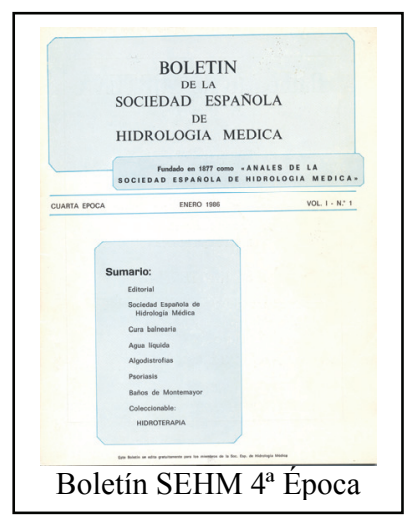
publicación del Boletín de la Sociedad Española de Hidrología Médica en su cuarta época, quedando a su cargo la dirección y como jefe de redacción la Doctora Josefina San Martín.

Permaneció como presidente de la Sociedad hasta 1991, en noviembre de ese año, La Sociedad Española de Hidrología Médica le rindió un homenaje de admiración en un acto celebrado en la sede de la misma, en la que intervinieron la doctora Josefina San Martín entonces presidenta de la citada sociedad y los hidrólogos Antonio Salces Blesa, José Maria Álvaro Gracia, y Agustín Valero Castejón. .

Durante su actividad como hidrólogo ha actuado como, organizador y ponente oficial de numerosos congresos internacionales y nacionales, simposios, cursos, reuniones etc. entre las que destacamos:

- Ponente oficial en el $5^{\circ}$ Congreso Internacional de Medicina Neo-Hipocrática de Montpellier en 1962.

- Ponente oficial en el Congreso Internacional de Hidrología de Baden Baden en 1962.

- Ponente oficial en el $1^{\circ}$ Congreso Latino Americano de Aguas Termales, celebrado en Carhué Lago Epecuen (Argentina) en 1969.

- Ponente oficial en el Congreso Internacional de Hidrotermalismo, celebrado en Estoril (Portugal) en 1970.

- Ponente oficial en la Reunión de "Europa Médica" celebrada en Lisboa en 1971.

- Ponente oficial en el Coloquio Termal de Outono, de Monfortinho (Portugal) en 1972.

- Ponente oficial del Symposium Internacional sobre Termalismo. en Zaragoza. 1972.

- Director de la Mesa redonda sobre Peloidoterapia celebrada en Dax (Francia) en 1974. 
- Ponente oficial del Coloquio Termal Açoreano, Azores junio 1974.

- Ponente oficial en Curso de Hidrología Médica y Reumatología de la Universidad de Tucumán (Argentina) en 1980.

- Presidente del $18^{\circ}$ Congreso Internacional de Talasoterapia de Las Palmas de Gran Canaria en 1981.

- Presidente del $17^{\circ}$ Congreso Internacional de Termalismo Médico ISMH en Azores (Portugal). 1982.

- Ponente oficial en las Jornadas Nacionales sobre Hidrología Médica de Sevilla.

- Ponente oficial en las Jornadas sobre Medicina y Balnearios en Caldas de Montbuy de 1984.

- Ponente oficial en las Jornadas sobre Medicina Balneoterápica de Euskadi en Cestona 1984.

- Ponente oficial en las Jornadas Gallegas de Balneoterapia de Carballino, Orense. 1984.

- Coorganizador de las Giornate mondiali di Termalismo . Milan 1984

- Copresidente del Encontro Luso Español de Hidrología Médica de Caldas da Reina, Portugal de 1985.

- Copresidente del Coloquio Termal do Alto Tàmega en Chaves y Verin de 1986.

- Copresidente de las Jornadas de Turismo Termal celebradas en Archena y Fortuna. Murcia en 1986.

- Copresidente de las $1^{\text {a }}$ Jornadas Técnicas de Turismo y Tercera Edad de Alicante de 1986-

- Copresidente del Seminario de Hidrología Médica del Balneario de Blancafort en La Garriga de 1987.

- Copresidente del Coloquio Hispano Portugués de 1987.

- Organizador y presidente del Congreso Latino de Hidrología Médica de la SEHM celebrado en Caldas de Malavella en 1988.

- Presidente del Comité Científico del $31^{\circ}$ Congreso de la ISMH celebrado en Madrid en 1989.

- Ponente en el Simposio sobre Hidrología Médica celebrado en el $4^{\circ}$ Congreso del IRMA en Madrid en 1990.

La magnitud de su labor en el campo de la Hidrología Médica ha sido apreciada y reconocida en todo su valor por los hidrólogos de todo el mundo que le han hecho miembro de sus Instituciones más importantes. Manuel Armijo ha sido miembro de Honor de la International Society of Medical Hidrology, miembro de Honor de la Sociedad Portuguesa de Hidrología Médica, de la Sociedad Argentina de Estudios termales, miembro Corresponsal de la Deutsche Gesellschaft für Balneologie... . 


\section{MANUEL ARMIJO VALENZUELA ACADÉMICO DE LA REAL ACADEMIA NACIONAL DE MEDICINA}

En sesión celebrada el 24 de Junio de 1975 la Real Academia Nacional de Medicina eligió por unanimidad a don Manuel Armijo Valenzuela como académico electo sucediendo a don Carlos Gil y Gil en el sillón número 28, en la Sección V Farmacología y Terapéutica.

El sillón 28 de Terapéutica Física había sido ocupado previamente por los doctores Federico Rubio y Galí en 1874, Luis Guedea Calvo en 1908, Vicente Gimeno Rodríguez-Jaén en 1923 y Carlos Gil y Gil en 1946.

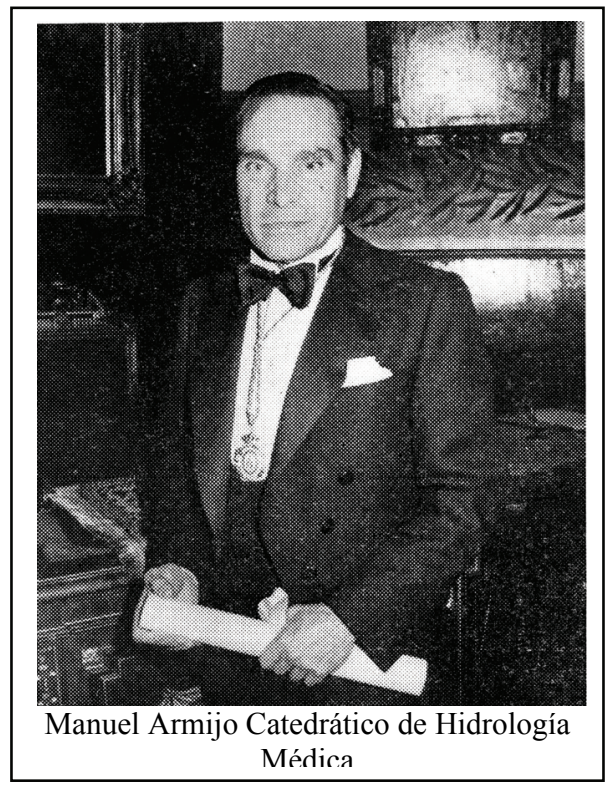

El 16 de diciembre de 1975 tomó posesión como Académico de Número de la Real Academia Nacional de Medicina, apadrinado por los dos académicos más modernos Excmo. Señores D. Antonio Gallego Fernández y D. Hipólito Durán Sacristán.

Concedida la palabra por el presidente titular de la Corporación, el excelentísimo Sr. D. Manuel Bermejillo y Martínez, el profesor Armijo Valenzuela dio lectura a su discurso de ingreso sobre el tema "Acciones sobre el organismo humano de las aplicaciones generales termo bifásicas (Sauna Finlandesa)", la contestación corrió a cargo del Excmo. Sr. D. Benigno Lorenzo Velázquez.

El discurso de ingreso lo había preparado cuidadosamente y no sólo era un trabajo de revisión bibliográfica, sino que incluía un estudio práctico de la variación de la composición del sudor de los usuarios de sauna, a los que él mismo buscó y cuyas muestras recogía puntualmente para luego ser analizadas en el laboratorio de la Cátedra.de Hidrología Médica.

Desde entonces acudió puntualmente a las reuniones de la Corporación interviniendo en diferentes sesiones con las disertaciones que reunimos cronológicamente en el anexo dedicado a su producción científica.

En 1991 fue nombrado Académico de Honor de La Real Academia de Medicina de Zaragoza y en 1999 Miembro de la Orden Civil de Sanidad. El Ateneo de Zaragoza le invitó a inaugurar el curso 1992, pronunciando un bello y documentado discurso titulado "La Balneación en el arte pictórico" en donde demostró su amplia cultura. 


\section{PRESIDENTE DE LABORATORIOS FARMABIÓN}

El prematuro y repentino fallecimiento de Juan José Alonso Grijalba en 1962 llevó a Manuel Armijo a tener que hacerse cargo como Presidente de la empresa Farmabión S.A, radicada en Madrid en un emblemático edificio diseñado en 1958 por el arquitecto Miguel Fisac Serna.

Seguramente nunca hubiera pensado el doctor Armijo Valenzuela verse involu-

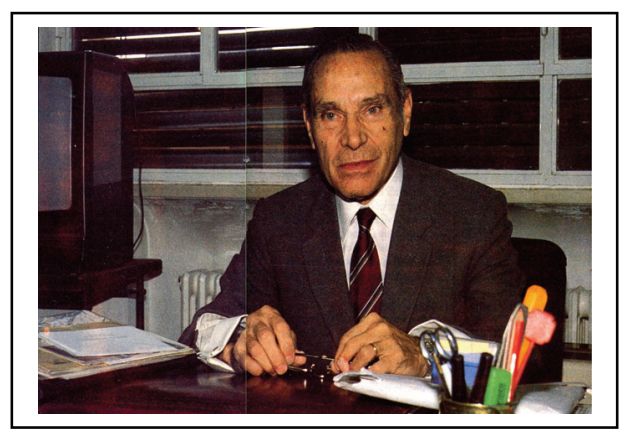
crado en este tipo de labores, pero cuando la obligación familiar le llevó a este cometido lo realizó brillantemente. Se rodeó de una buena "cuadrilla" de colaboradores, baste decir que, además de otros excelentes técnicos y administrativos, en su plantilla reunió a tres posteriores catedráticos y un profesor titular de la Universidad Complutense y a un profesor adjunto de la Universidad de Santiago de Compostela, con los que apuntaló los departamentos de Tecnología Farmacéutica, Farmacia Galénica, Farmacología y Análisis y Control.

$\mathrm{Su}$ dirección llevó a este laboratorio a escalar muchos puestos en el mercado español, aportando el doctor Armijo su metódico y puntual trabajo diario, su experiencia y su buen hacer para resolver cuantas cuestiones planteaba el día a día. Cuando actualmente me encuentro con trabajadores de aquella empresa todos le recuerdan con afecto especialmente por su eficacia y generosidad.

\section{SU FAMILIA}

Manuel Armijo casó en 1946 con Maria del Carmen Alonso Cillero de cuyo matrimonio nació su hijo Manuel Armijo Alonso. El destino quiso otra vez que se trenzasen las vocaciones de los hijos de los hermanos Armijo Valenzuela, Manuel Armijo Alonso siguió los pasos de mi padre estudiando leyes y yo me acerqué a las ciencias de la salud. Los hermanos Armijo Valenzuela se preocuparon por la formación de sus vástagos y sobrinos y cuando ya en la tercera generación alguien estudió medicina, mi hija Onica, don Manuel, le regaló, con mucha emoción, sus libros, que ella utilizó y conserva cuidadosamente.

Además de su afición al futbol, ya citada, don Manuel tenía otras en las que aprovechó su habilidad manual. Podía arreglar todo tipo de objetos, me consta que reparó en plena operación aparatos de cirugía, cuando estos no estaban tan perfeccionados ni en número tan adecuado como ahora. Cuando su actividad académica se lo permitió se dedicó a la pintura, a la escultura y al modelado, sus cuadros y figuras, sólo permitió que fueran contempladas por sus más allegados, pero cuando lo 
hicieron algunos profesionales comentaron que sus esculturas estaban muy por encima de lo que solían hacer los autodidactas.

Como final quiero añadir que estas últimas líneas están redactadas después de su fallecimiento, estoy seguro que otros escribirán mejor su biografía, pero nadie podrá ganarme en el cariño y admiración que he puesto al esbozar el retrato de quien durante setenta años ha sido mi tío y maestro.

\section{Agradecimientos}

Deseo agradecer la ayuda de todas aquellas personas que me han ayudado en la realización de esta semblanza. Especialmente a Manuel Armijo Alonso, que me proporcionó la información que guardaba su padre sobre sus actividades, a Josefina San Martín, que puso a mi entera disposición el material que ella había recogido sobre su maestro, a Luis Pablo Rodríguez Rodríguez, que generosamente me aportó la bibliografía de tantos trabajos que compartió con su también maestro, a Iluninada Corvillo y Francisco Maraver, mis compañeros de Cátedra, por su paciencia y ayuda en la búsqueda de información y a Manuela Crego subdirectora de la Biblioteca de Medicina de la UCM por su profesional y experta colaboración.

\section{BIBLIOGRAFÍA}

Mendoza F. Fermín Murillo. Biografía. Semanario Equipo. Zaragoza. 1962.

Armijo Valenzuela, M. Currículo. Manuscrito inédito. 1963

Armijo Valenzuela, M. Curriculum vitae que para aspirar a una plaza de académico de número de la Real Academia Nacional de medicina, presenta el profesor D. Manuel Armijo Valenzuela. Manuscrito inédito. 1975

Real Academia Nacional de Medicina. Figuras académicas. Boletín informativo. Julio-agosto-septiembre. 1975; 245

Real Academia Nacional de Medicina. Recepción del Profesor Armijo Valenzuela. Boletín informativo. Octubre-noviembre -diciembre.1975; 246

Armijo-Valenzuela, M. Acciones sobe el organismo humano de las aplicaciones generales termo bifásicas (Sauna finlandesa). Real Academia Nacional de Medicina. Madrid. 1975. 5-158

Lorenzo Velázquez, B. Discurso de contestación. Real Academia Nacional de Medicina. Madrid. 1975. 161-167.

Gómez-Santos M. Conversaciones con don Manuel Armijo Valenzuela. Tribuna Médica: 1983, Abril 22. p. 2

Gómez-Santos, M. Conversaciones con don Manuel Armijo Valenzuela. Tribuna Médica: 1983, Abril 29. p. 2. 
Gómez-Santos, M. Conversaciones con don Manuel Armijo Valenzuela. Tribuna Médica: 1983, Mayo 6. p. 2

Lorenzo-Velázquez B. Memorias. Enseñanzas de una vida. Madrid: Editorial GARSI;1984.

Zubiri A, El profesor Velázquez y los médicos aragoneses. Heraldo de Aragón. 29 de junio de 1986

Anónimo. Especialidades Médicas. Hidrología. OMC 1990; 7: 44-50.

San Martín-Bacaicoa, J. Homenaje al profesor D. Manuel Armijo Valenzuela.. 1991. Manuscrito inédito.

Anónimo. Homenaje al Profesor Armijo Valenzuela. Madrid Médico. 1991; $11: 64$

Anónimo. Homenaje de la S E H M al Profesor Manuel Armijo Valenzuela. Bol. Soc. Esp. Hidrol Med. 1992; 8(1): 9-11

Maraver F, Aguilera L, Corvillo I, Morer C, Armijo F. L'Enseignement de 1'Hidrologie à 1'Univerdité Complutense de Madrid. Trente années de 1'Ecole professionnelle d'Hydrologie Médicale et d'Hydrothérapie. Press Therm Climat 2007; 144: 167-176.

Biblioteca de Medicina. 100 años haciendo ciencia: La Cátedra de Hidrología Médica de la Universidad Española (1912-2012). Nuevas orientaciones: Armijo Valenzuela y la Escuela de Hidrología Médica Facultad de Medicina. Universidad Complutense. 2012, 17 abril. http://www.ucm.es/BUCM/med/doc19613.pdf

Rodríguez LP. Excmo Sr. D. Manuel Armijo Valenzuela, Catedrático (19631986). Acto académico en Conmemoración del Centenario de la Creación de la Cátedra de Hidrología Médica de la Universidad Española 1912-2012. Facultad de Medicina. UCM. 2012, 17 abril. http://www.ucm.es/BUCM/med/doc19731.pdf

Armijo F. La Cátedra de Hidrología Médica y los análisis de aguas minerales. Acto académico en Conmemoración del Centenario de la Creación de la Cátedra de Hidrología Médica de la Universidad Española 1912-2012. Facultad de Medicina. UCM. 2012, 17 abril. http://www.ucm.es/BUCM/med/doc19733.pdf

Solsona F. Manuel Armijo Valenzuela. Heraldo de Aragón 2012; 663 de Junio

Luis Pablo Rodríguez Rodríguez, Discurso de precepto, en nombre de la Academia en la Solemne Sesión Necrológica en memoria del Excmo. Sr. D. Manuel Armijo Valenzuela. 19 de junio de 2012. Real Academia Nacional de Medicina. Madrid. En prensa

\section{ANEXO}

En este anexo he procurado reunir la producción científica del doctor Manuel Armijo Valenzuela. Dada su dilatada y activa vida profesional, no ha sido tarea fácil buscar y recoger su trabajo, plasmado en libros, artículos, ponencias, conferencias, cursos... . 
En las publicaciones anteriores a 1978 se ha mantenido la grafía de las diferentes publicaciones procurando darles una sistemática lo más homogénea posible. A partir de ese año se han utilizado las reglas de Vancouver siempre que los trabajos han sido accesibles para completarlas.

\section{Producción científica}

Manuel de Armijo Valenzuela. Algunas acciones farmacológicas del salicilato sódico y sus relaciones con el shock peptónico e histamínico [Tesis]. Madrid: Universidad Central, Facultad de Medicina; 1942.

Armijo M., García de Jalón P., García de Leániz J, Andolz F. Insulina. Farmacología y Terapéutica 1943. 4

Armijo M. Estrógenos sintéticos. . Farmacología y Terapéutica 1943. 347-364.

Armijo M, García de Jalón P. Algunas acciones farmacológicas de los estrógenos sintéticos. . Farmacología y Terapéutica 1943. 506-511

Armijo M. Hormonas sexuales masculinas. Farmacoterapia Actual. 1944; 1(2): 17-28.

Lorenzo Velázquez B, Armijo M. Contribución a la farmacología de algunos simpaticomiméticos (adrenérgicos) por vía suboccipital. Farmacoterapia Actual. 1944; 1(2): 29-34.

Armijo M. La medicación salicilada. Curso de perfeccionamiento médico. Madrid 1944.

Armijo M. Ácido pantoténico. Farmacoterapia Actual. 1944; 1(6): 5-12.

Armijo M. Acción sensibilizante del salicilato sódico para los anestésicos generales. Farmacoterapia Actual. 1944; 1(6): 15-19.

Armijo M. Acumulo de vitamina A en el organismo. Actas de las Jornadas Médicas de Sevilla. 1944.

Armijo M., Samitier J. Polineuritis periférica por athiaminosis en enfermos tuberculosos. Revista Española de Tuberculosis. 1945. 14 (124) julio. p. 515-519

Armijo M., Samitier J. Consideraciones sobre el "filtro pulmonar" (recidivas del paludismo en enfermos de tuberculosis pulmonar). Revista Española de Tuberculosis. 1945. 14(126) septiembre. p. 687-697.

Armijo M., Samitier J. Modernas orientaciones de la quimioterapia antituberculosa. Revista Española de Tuberculosis. 1945. 14(128) Noviembre. p. 853-867

Armijo M. Acción profiláctica de las dosis masivas de vitamina A- En: Jornadas Médicas. Sevilla. 1945, mayo.

Armijo M. Demostración experimental del diferente comportamiento de las aguas mineromedicinales, naturales y preparadas artificialmente, sobre la curva ponderal. Farmacoterapia Actual. 1945; 2(1): 45-47.

Armijo M. Acción profiláctica de las dosis masivas de vitamina A. Farmacoterapia Actual. 1945; 2(2): 104-122. 
Armijo M, García Jalón P. Modificaciones en las respuestas glucémicas por la administración previa de estrógenos sintéticos. Farmacoterapia Actual. 1945; 2(9): 165-168.

Armijo M, García Leániz J. Tratamiento del cáncer por los estrógenos sintéticos. Farmacoterapia Actual. 1945; 2(14): 508-513.

Armijo M. Toxicidad de las grandes dosis de vitamina $\mathrm{C}$ y de su asociación con las sales cálcicas. Farmacoterapia Actual. 1945; II (17): 712-721.

Armijo M, García Leániz J. Estudio experimental de la acción tóxica del estilbestrol. Farmacoterapia Actual. 1945; II (18): 787-792.

Armijo M. Memoria de las aguas minero-medicinales de Carballino. Dirección General de Sanidad. 1945.

Armijo M, Samitier J. Sulfonas: Su importancia en Terapéutica. Farmacoterapia Actual. 1946; III (20): 86-93.

Armijo M, Urtasun C. Un nuevo antibiótico: La estreptomicina. Farmacoterapia Actual. 1946; III (22): 234-241.

Lorenzo Velázquez, P, Armijo M, Andolz F. Contribución al estudio de la acción bacteriostática de los estilbenos. Farmacoterapia Actual. 1946; III (22): 247249.

Armijo M. Estudio experimental de las modificaciones ejercidas por el salicilato sódico sobre la acción acetilcolínica. Farmacoterapia Actual. 1946; III (28): 634689.

Armijo M., García de Jalón P., García de Leániz , Andolz J. Estrógenos sintéticos Farmacoterapia Actual. 1946.

Armijo Valenzuela, Manuel de.,- Tratamiento farmacológico e las tripanosomiasis humanas. Med. Colon. Madrid, 1946 7(4):318-330,

Armijo M. Toxicidad de las grandes dosis de Vitamina C. Odontoiatría. 1946; 25,8 .

Armijo M. Memoria de las aguas minero-medicinales de Carballino. Dirección General de Sanidad. 1946.

Santos-Ruiz A, Carrato-Ibáñez A, Armijo Valenzuela M. Las hormonas en medicina. Madrid: Publicaciones Científicas Alter. 1947; 8: 217.

M. Mateo Tinao, M. de Armijo Valenzuela. Ejercicios prácticos de farmacología experimental. Zaragoza. Magisterio Español; 1947; p 98

Armijo M. Memoria de las aguas minero-medicinales de Carballino. Dirección General de Sanidad. 1947.

Armijo M. Reumatismos tributarios de la Terapéutica hidromineral en relación con los manantiales españoles. Real Academia de Medicina de Zaragoza.1947.

Armijo M. Valoración de antihelmínticos con las técnicas de la escuela portuguesa. Farmacoterapia Actual. 1948; 5(53-54): 593-600.

Armijo M., Toscano Rico, Action de quelques phénols et éteres phénoliques sur l'ascaris suis. Arch. Portugaises Sc. Biol. 1948; 9: 170. 
Armijo M. Tratamiento hidromineral de las neuralgias reumáticas. Revista española de Farmacología y Terapéutica. Junio 1948.

Armijo. M. Los antibióticos en Terapéutica. Curso de Perfeccionamiento Médico. Cádiz. 1948.

Armijo M. Valoración de antihelmínticos con la técnica de la escuela portuguesa. Farmacoterapia actual. 1948; 53: 593

Armijo M. Sur le mode d'action de quelques anthelmintiques. Schweizerischer Verein der Phys. U. Pharmakologen. Berna (Suiza). 1948.

Armijo M. Memoria de las aguas minero-medicinales de Carballino. Dirección General de Sanidad. 1948.

Armijo M. Memoria de las aguas minero-medicinales de Fitero Viejo. Dirección General de Sanidad. 1951.

Aguirre D, Armijo M. Estudio experimental de la absorción y utilización de la vitamina "A" administrada por vía rectal. Arch. Inst. Farmacol. Exp. 1951 3(1) 88109

Armijo M. Fisiopatología y clínica de las glándulas suprarrenales. En: E. Romero. Madrid: Paz Montalvo; 1951. 395 p

Armijo M. Aplicaciones terapéuticas de los corticosteroides. Curso de Endocrinología. Valladolid. 1951.

Armijo M. Memoria de las aguas minero-medicinales de Fitero Viejo. Dirección General de Sanidad 1952.

Armijo M. Acción de los antibióticos sobre cultivos de tejidos. An Inst Farm Esp. 1953; II: 383-391.

Armijo M. Ganglioplegiques et vois digestives. En: Extrait des Journées Therapeútiques de Paris. 1953.

Manuel de Armijo Valenzuela y Daniel Aguirre Miqueo. Acción de la vitamina B1 sobre el útero aislado y sobre su sensibilidad a la pituitrina y otros oxitócicos. En: Homenaje ofrecido a Teófilo Hernando por sus amigos y discípulos. Editorial Hernando. Madrid. 1953. p. 29-36.

Armijo. M Farmacología de los factores hipofisarios. Curso de Endocrinología. Valladolid.1953.

Armijo M. Interés terapéutico de la asociación de hormonas sexuales. Curso de la Academia de Alumnos Internos de la Facultad de Medicina. Valladolid. 1953.

Armijo M. Actividad espasmolítica de la lobelina. $1^{\text {a }}$ Reunión Nacional de Ciencias Fisiológicas. Madrid 1953.

Armijo M. Acción broncodilatadora de la lobelina. $1^{\text {a }}$ Reunión Nacional de Ciencias Fisiológicas. Madrid 1953.

Armijo M., Aguirre D. Estudio comparativo de los efectos de la vagotonía y de los inhibidores ganglionares y postganglionares mediante la técnica de Shay. Arch. Inst. Farmacol. Exp. 1953. 5(1 y2). p. 288-297. 
Armijo M., Aguirre D. Acción broncodilatadora de la lobelina frente a los broncoespasmos producidos por aerosoles de histamina y acetilcolina. Arch. Inst. Farmacol. Exp. 1953. 5(1 y 2) p. 298-304

Armijo M, Aguirre D. Actividad espasmolítica de la lobelina sobre el intestino aislado frente a varios agentes contracturantes. Arch. Inst. Farmacol. Exp.1953. 5(1 y 2) p.304-314.

Armijo M. Gangliopegiques et voies digestives. Journes Therapeutiques. Paris. (Francia). 1953.

Armijo M. Hipófisis. En: Romero E. Fundamento. Patología y Clínica. 1954. Barcelona. Científico Médica. p 452.

Armijo M., Watemberg JM. Acción de la tetraciclina, terramicina y aureomicina sobre cultivos de tejidos. Arch. Inst. Farmacol. Exp.1954. VI (I). p. 77-90.

Armijo Valenzuela Manuel de. Memoria del CSIC. Años 1952-1954. 416.

Armijo M., Ferrández JA. Acción modificadora de la actividad proteolítica de la pepsina. En: Actas de la $2^{\text {a }}$ Reunión de la Sociedad Española de Ciencias Fisiológicas. 1955.

Armijo M., Watemberg JM. Tolerancia de los fibroblastos. En: Actas de la $2^{\text {a }}$ Reunión de la Sociedad Española de Ciencias Fisiológicas. 1955.

Armijo M. De la receta magistral a la especialidad farmacéutica. Cursillo de orientación Médico Rural. Valladolid. 1955.

Armijo M. Opoterapia hipofisaria. Cursillo sobre Hipófisis. Cruz Roja Española. Madrid. 1955.

Armijo M. Acción de los Ganglioplégicos sobre cultivos de tejidos. $2^{\text {a }}$ Reunión Nacional de Ciencias Fisiológicas. Barcelona. 1955.

Armijo M. Acción de los simpaticolíticos sobre cultivos de tejidos. $2^{\text {a }}$ Reunión Nacional de Ciencias Fisiológicas. Barcelona. 1955.

Armijo M. Modificaciones de la acción proteolítica de la pepsina. 2 a Reunión Nacional de Ciencias Fisiológicas. Barcelona. 1955.

Armijo M., Hontoria T. Estudio de los efectos de la isoniacida y estreptomicina en combinación química sobre cultivos de tejidos. Arch. Inst. Farmacol. Exp. 1955; $8(1$ y 2$)$. p. $104-108$.

Hontoria T, Armijo M. Estudio de los efectos de la hidracida del ácido isonicotínico y algunos de sus derivados sobre cultivos de tejidos. Arch. Inst. Farmacol. Exp. 1955; 8(1 y 2). p. 109-113.

Armijo M. Memoria de las aguas minero-medicinales de La Toja. Dirección General de Sanidad. 1955.

Armijo M. Les anticholinergiques dans le traitement de l'ulcere peptique. En: Extrait des Journées Therapeútiques de Paris. Journees Therapeutiques de Paris sur le traitement de l'ulcus gastrique, Les Medications Hemostatiques 1956.

Armijo M., Izquierdo M. Contribución al estudio de la toxicidad del cloranfenicol. Arch. Inst. Farmacol. Exp .1956; 8(1 y 2). 
Armijo M., Izquierdo M. Influencia de la esterificación y yodación de la penicilina en sus acciones sobre los cultivos de tejidos. Arch. Inst. Farmacol. Exp.1956; $8(1$ y 2$): 124-131$.

Armijo M. Influencia del radical ácido en la toxicidad de la estreptomicina. $3^{\mathrm{a}}$ Reunión Nacional de Ciencias Fisiológicas. 1956.

Armijo M. Modificaciones imprimidas por la esterificación en la acción de la penicilina. $3^{\text {a }}$ Reunión Nacional de Ciencias Fisiológicas. 1956.

Armijo M., Izquierdo M. Influencia de los antihistamínicos sobre la proteolisis por pepsina in vitro. Arch. Inst. Farmacol. Exp. 1957; 9(1 y 2). 182-192.

Hernando T, Armijo M. Los anticolinérgicos en el tratamiento de la úlcera péptica. Rev Esp Enferm Apar Dig Nutr. 1957 Mar-Apr;16(2):173-93.

Armijo Valenzuela Manuel de. Memoria del CSIC. Años 1955-1957. 358.

Armijo M., Izquierdo M. Efectos de la asociación con piridoxina, glicocola y acido glutámico sobre la toxicidad de la estreptomicina y dihidroestreptomicina. Arch. Inst. Farmacol. Exp.1958; 8(1 y 2).

Armijo M., Izquierdo M. Efecto del ácido salicílico, PAS, acido benzoico y PABA sobre la toxicidad de la estreptomicina e dihidroestreptomicina. Arch. Inst. Farmacol. Exp. 1958.

Armijo M., Izquierdo M. Efectos de la hidracida del acido isonicotínico sobre la toxicidad de la estreptomicina e dihidroestreptomicina. Arch. Inst. Farmacol. Exp. 1958.

Armijo M., Izquierdo M. Modificaciones producidas en un índice de toxicidad de la dihidroestreptomicina por la asociación de diferentes sustancias. Arch. Inst. Farmacol. Exp.1958; X (I y II): 121-134.

Armijo Valenzuela Manuel de. Memoria del CSIC. Años 1958. 147.

Armijo M. Los complejos naturales y los productos sintéticos en terapéutica. O Médico. 1959; 407; 16.

Armijo M. Penicilina y bencilpenicilina. En: Actas de la $5^{\text {a }}$ Reunión de la Soc. Esp. Cienc. Fisiol. 1959. diciembre

Armijo M. Cirrosis experimental y ácido pangámico. $5^{\text {a }}$ Reunión Nacional de la Soc. Esp. Cienc Fisiol. Madrid. 1959, diciembre.

Armijo M. La anemia saturnina en cobayas, como índice de actividad de los extractos hepáticos. 5 $5^{\text {a }}$ Reunión Nacional de Ciencias Fisiológicas. Madrid. 1959, diciembre.

Armijo M. Influencia de los antihistamínicos sobre la actividad de la penicilina in vitro. $5^{\text {a }}$ Reunión Nacional de Ciencias Fisiológicas. Madrid. 1959, diciembre.

Armijo M. Influencia de la esterificación en la acción de la bencil penicilina. $5^{\mathrm{a}}$ Reunión Nacional de Ciencias Fisiológicas. Madrid. 1959 diciembre.

Armijo M, Izquierdo M. Influencia de los antihistamínicos de síntesis sobre la actividad de la penicilina in vitro. Arch. Inst. Farmacol. Exp. 1959; 9(1 y 2). 90-96. 
Armijo M., Izquierdo M., Rodríguez LP. Modificaciones producidas en un índice de toxicidad de la dihidroestreptomicina por la asociación de diferentes sustancias. Arch. Inst. Farmacol. Exp.1959; XI (1 y 2): 97-101.

Izquierdo M, Aguirre D, Armijo M. Efecto de la vitamina B15.sobre la degeneración hepática producida por Cl4C. Arch. Inst. Farmacol. 1959; XI (I y II). 102115 .

Armijo M. La asociación dihidroestreptomicina hidracida del ácido isonicotinil en Terapéutica. Facultad de Medicina. Lisboa. 1959.

Armijo M. Estreptomicina y sus asociaciones con otros tuberculostáticos. Facultad de Medicina. Zaragoza. 1959.

Armijo Valenzuela Manuel de. Memoria del CSIC. Años 1959. 114.

Armijo M, Izquierdo M. Comportamiento de algunos esteres de la bencilpenicilina sobre cultivos de tejidos. Arch. Inst. Farmacol. Exp.1960; XII (II). 145-149.

Rodríguez, LP., Armijo, M. Penicilina y bencilpenicilina. Arch. Inst. Farmacol. Exp.1960; 14 (1 y 2).

Armijo. M Utilización de drogas por los deportistas. Servicios Sanitarios de Educación Nacional del Deporte. Madrid. 1960.

Armijo Valenzuela Manuel de. Memoria del CSIC. Año 1960. 125

Armijo M., Izquierdo M. Nicotinato de Estreptomicina. En: Actas de $6^{a}$ Reunión de la Sociedad Esp Cienc Fisiol. 1961.

Armijo M. Doping. Servicios Sanitarios de Educación Nacional del Deporte. Madrid. 1961.

Armijo M. Crenoterapia en el Reumatismo. Curso sobre Reumatología Colegio de Médicos. Soria. 1961.

Armijo M. Memoria de las aguas minero-medicinales de Caldas de Oviedo. Dirección General de Sanidad. 1961.

Armijo M. Hidroterapia y Medicina del Deporte. Cursos Sanitarios de Educación Nacional del Deporte. Madrid. 1962.

Armijo M. Crenoterapia y Medicina del Deporte. Cursos Sanitarios de Educación Nacional del Deporte. Madrid. 1962.

Rodríguez LP., Armijo M. Estudio in vitro de la acción antiácida y antiséptica de diversos compuestos de aluminio. En: Actas de la $7^{a}$ Reunión de la Soc Esp Cienc Fisiol. Cádiz 1962; 25-27.

Armijo M. Bioensayo de la gonadotropina coriónica. En: Actas de la $7^{\mathrm{a}}$ Reunión de la Soc Esp Cienc Fisiol. Cádiz. 1962; 187

Rodríguez LP, Armijo M, Izquierdo M. Efectos producidos en la toxicidad del acido fenil quinolin carbónico, mediante la asociación de nicotinamida, pantotenato cálcico y vitamina B12 sobre cultivo de tejidos. En: Actas de la $7^{\text {a }}$ Reunión de la Soc Esp. Cienc Fisiol. Cádiz. 1962; 194-196.

Armijo M., Izquierdo M., Vazquez F. Toxicidad de un derivado hidrosoluble de tetraciclina. En: Actas de la 7 Reunión de la Soc Esp Cienc Fisiol. Cádiz. 1962. 
Rodríguez LP, Armijo M, Izquierdo M. Estudio de las tetraciclinas solubles mediante un índice de toxicidad. En: Actas de la $7^{\mathrm{a}}$ Reunión de la Soc Esp Cienc. Fisiol.Cádiz. 1962; 213-215.

Izquierdo M, Armijo M, Rodríguez LP. Tolerancia local de un nuevo derivado hidrosoluble de tetraciclina. En: Actas de la $7^{\mathrm{a}}$ Reunión de la Soc Esp Cienc Fisiol. Cádiz. 1962; 225-228.

Izquierdo M., Armijo M., Rodríguez LP. Potencia y espectro antibiótico de un nuevo derivado hidrosoluble de tetraciclina. En: Actas de la $7^{\mathrm{a}}$ Reunión de la Soc Esp Cienc Fisiol. Cádiz. 1962; 229-230.

Rodríguez LP., Armijo M., Aguirre D. El test de la acantosis en el estudio de los excipientes de pomadas. En: Actas de la $7^{a}$ Reunión de la Soc Esp Cienc Fisiol. Cádiz.1962: 1962; 256-266.

Armijo M., Aguirre. D. Acción de algunas aguas minero medicinales sobre la hepatotoxicidad del tetracloruro de carbono. Arch. Inst. Farmacol. Exp. 1962; 14(2): 187-196.

M. de Armijo Valenzuela. Crenoclimatoterapia del asma bronquial con especial referencia a su tratamiento en el Balneario de Caldas de Oviedo. Bol Soc Esp Hidrol Med Octubre 1962; 1(2): 13- 21.

Armijo M. Situación de la cura crenoclimática en España. Jornadas Internacionales de Medicina Hidrológica y Climática. Coimbra. 1962.

Armijo M. Reacciones termales observadas con la aplicación de aguas oligometálicas radiactivas. Jornadas Internacionales de Medicina Hidrológica y Climática. Coimbra. 1962.

Armijo M. Acquisitions récentes de la Thérapeutique thermale des affections hépato biliaires. En: Actas del Congrés International de Thermalisme. Baden Baden 1962.

Armijo M. Importance des rythmes biologiques. En: Actas del $5^{\circ}$ Congrès International de Medicine Neo Hippocrátique. Montpellier. 1962.

Armijo M. Consideraciones en torno a la cura balnearia. Bol Soc Esp Hidrol Med. 1963; 2(3): 11-23.

Armijo M., Aguirre D. Acción de algunas aguas minero-medicinales sobre el crecimiento y sobre la hepatotoxicidad del tetracloruro de carbono en las ratas (Aguas de Lanjarón, Cofrentes y Carballino). Arch. Inst. Farmacol. Exp.1963; 15(1): 95

Armijo M., Palomo T. Efectos secundarios ocultos de las drogas psicoestimulantes, Arch. Inst. Farmacol. Exp.1963; 15(2): 179-183.

Armijo M. Mecanismo de acción de las aguas minero-medicinales. Arch. Fac Med.Madr.1963; 4(5): 277- 300.

Armijo M. Reacciones Termales Observadas con la Aplicación de Aguas Oligometálicas Radiactivas (Caldas de Oviedo). O Médico. 1963; 617. 
Armijo M. Consideraciones farmacológicas sobre los productos de asociación más utilizadas en el tratamiento de la tuberculosis. A Medicina Contemporânea. 1964; 67.

Armijo M., Rodríguez LP., San Román J. Estudio in vitro de la acción neutralizante de diversas aguas mineromedicinales españolas. En: Actas de la $8^{\text {a }}$ Reunión de la Soc Esp Cienc Fisiol. 1964; 19-20.

Armijo M., Rodríguez LP. Influencia de algunas aguas mineromedicinales sobre los glóbulos rojos y la viscosidad sanguínea. En: Actas de la $8^{\text {a }}$ Reunión de la Soc Esp Cienc Fisiol. 1964; 141-144.

Rodríguez LP., Armijo M. Estudio comparativo de las tetraciclinas hidrosolubles mediante determinacion de DE50 y DI50 en cultivo de tejidos. En: Actas de la $8^{\mathrm{a}}$ Reunión de la Soc Esp Cienc Fisiol. 1964; 227-231.

Rodríguez LP., Armijo M. Estudio sobre algunos efectos metabólicos de la isoniazidilmetil tetraciclina. Arch. Inst. Farmacol. Exp.1964; 16(1): 35-44.

Armijo M., Rodríguez LP. Estudio comparativo de las tetraciclinas hidrosolubles en cultivos de tejido embrionario. Arch. Inst. Farmacol. Exp.1964; 16(1): 69-83.

Armijo M. La cura hidromineral en la vejez. Bol Soc Esp Hidrol Med. 1964; 3 (7): 3-11.

Armijo M. Las aguas mineros-medicinales en las alteraciones hepáticas. Bol Soc Esp Hidrol Med. 1964; 3 (8): 14-22.

Armijo M. Psicofármacos. Arch. Fac. Med. Madr.1964; V(5): 299- 333.

Rodríguez LP, Armijo M. Efectos experimentales del propionato de testosterona y de la gonadotropina coríonica en asociación. Arch. Inst. Farmacol. Exp. 1965; 17(1): 71-81.

Rodríguez LP, Armijo M. Estudio experimental sobre asociación hormonal: gonadotropina coríonica, propionato de testosterona. Arch. Inst. Farmacol. Exp.1965; 17(1): 103-109.

Goldbáun CR., Armijo M., Rodríguez LP. Estudio experimental sobre la ototoxicidad de los fármacos: y sal sódica del acido fusídico. Arch. Inst. Farmacol. Exp. 1965; 17(1): 111-125.

Armijo M, Rodríguez LP, Aguirre D. Acción de algunas aguas mineromedicinales sobre el crecimiento y sobre la hepatotoxicidad del tetracloruro de carbono en las ratas. Arch. Inst. Farmacol. Exp.1965; 17(2): 127-136.

Armijo Valenzuela M. Antibioterapia de las Infecciones Estafilocócicas. Revista Informativa y Cultural del Ilustre Colegio Oficial de Médicos de Ciudad Real.1965; 2:15-29.

Armijo Valenzuela de M. Mecanismo de accio de las águas Minero-medicinales. En: Publicaçoes do Instituto de Climatologia e Hidrologia da Universidade de Coimbra. 1965; 20.

Armijo Valenzuela M., Lobato De Guimarães J. Acquisitions récentes de la thérapeutique thermale des affections hépato-biliaires en Espagne et au Portugal. Publ. Inst. Climatologia e Hidrologia Univ Coimbra. 1965; 20. 
Armijo Valenzuela M. Consideraciones generales sobre las aguas mineromedicinales. O Médico. 1965; 725.

Armijo Valenzuela de M. Farmacoterapia de la aterosclerosis. Arch. Fac. Med. Madr.1966; 9(4) 213- 227.

Armijo Valenzuela de M. Acción biológica de las aguas mineromedicinales. VII Curso de Ampliación de Estudios. Facultad de Medicina. Zaragoza. 1966. 18-23 de abril.

M. Armijo, L.P. Rodríguez, J. San Román, J. A. Rodríguez, A. Velasco. Acción de la gonadotropina coríonica, en relación con los efectos que produce la clorpromazina sobre testículos y vesículas seminales en animales de experimentación. Arch. Inst. Farmacol. Exp.1966; 18(1): 13-17.

L.P. Rodríguez, M. Armijo, J. A. Rodríguez, J. San Román, A. Velasco. El D.M.S.O. como inhibidor de la reacción anafilactoide producida por dextrano. Arch. Inst. Farmacol. Exp.1966; 18(1): 19-25.

M. Armijo, L.P. Rodríguez, A. Velasco, J. A. Rodríguez, J. San Román. El D.M.S.O "in vivo" sobre el consumo de oxígeno hepático. Arch. Inst. Farmacol. Exp.1966; 18(I): 97-101

Armijo M, Rodríguez LP, Velasco A, Rodríguez JA, San Román J. Efecto del DMSO sobre el consumo hepático de oxigeno. Arch Inst Farmacol Exp (Madr). 1966; 18(2):65-72. Spanish.

L.P. Rodríguez, M. Armijo, J. A. Rodríguez, J. San Román, A. Velasco. Efectos del DMSO sobre presión y respiración. Arch. Inst. Farmacol. Exp. 1966; 18(2): 97101.

L Velázquez, M. Armijo, L. P. Rodríguez Bioensayo de la asociación hormonal: testosterona, gonadotropina coriónica. En Libro Homenaje al Prof. Belloch Montesinos. Ed. Ecir. Valencia. 1966.

B. Lorenzo-Velázquez, M. de Armijo y L. Rodríguez. Bioensayo de la asociación hormonal: testosterona-gonadotropina coríonica. Arch. Inst. Farmacol. Exp. 1967; 19(1): 9-23.

Armijo M, Rodríguez LP, Rodríguez JA, San Román J, Velasco A. Efectos del DMSO in vitro sobre el consumo de oxigeno. Arch. Inst. Farmacol. Exp. 1967; 19(1): 24-47.

L.P. Rodríguez, J. A. Rodríguez, J. San Román, M. Armijo y B. LorenzoVelázquez. Modificaciones cariométricas uterinas por testosterona y gonadotropina coriónica. Arch. Inst. Farmacol. Exp.1967; 19(1): 49-62.

J.A. Rodríguez, M. de Armijo, L.P. Rodríguez. Estudio antiinflamatorio experimental con tetraciclinas hidrosolubles. Arch. Inst. Farmacol. Exp.1967; 19(2): 103117.

M. Armijo Tratamientos crenoterápica de las enfermedades reumáticas. IX Curso sobre Enfermedades Reumáticas. Facultad de medicina. Madrid. 196710 marzo 
Rodríguez LP., Armijo M., Rodríguez JA., San Román J., Velasco A. Clorpromazina-gonadotropina coríonica sobre órganos genitales masculinos. En: Actas de la 10a Reunión de la Soc Esp Cienc Fisiol. 1967; 229-231.

Armijo M., Rodríguez LP., Rodríguez JA., San Román J., Velasco A. Reacción anti anafiláctica del DMSO. En: Actas de la 10 Reunión de la Soc Esp Cienc Fisiol. 1967; 273-277.

Armijo M., Rodríguez LP., Velasco A., Rodríguez JA., San Román J. Efecto hipotensor del DMSO. En: Actas de la 10a Reunión de la Soc Esp Cienc Fisiol. 1967; 279-280.

Armijo M., Velasco A., Rodríguez LP., San Román J. Rodríguez JA. Acción del DMSO sobre respiración celular. En: Actas de la 10 Reunión de la Soc Esp Cienc Fisiol. 1967; 281-284.

Rodríguez JA., Rodríguez LP., San Román J., Armijo M. Acciones sobre distintas constantes fisiológicas producidas por tetraciclinas. En: Actas de la $11^{\text {a }}$ Reunión de la Soc Esp Cienc Fisiol. Madrid. 1968, diciembre; 209-210.

M. Armijo Tratamientos crenoterápica de las enfermedades reumáticas. X Curso sobre Enfermedades Reumáticas. Facultad de medicina. Madrid. 19689 marzo

M. de Armijo. Lección magistral primer curso de ATS, de Salus Infirmorum. Arch. Fac. Med. Madr.1968; 8(4): 440-441.

M. de Armijo Valenzuela. Crenoterapia de los reumatismos. Sociedad Española de Hidrología Médica. Madrid. 196818 de mayo.

M. de Armijo Valenzuela. Crenoterapia en los reumatismos. Academia Médico Quirúrgica Asturiana. Oviedo 1968. Mayo

M. de Armijo Valenzuela. Psicofármacos. En: Anales de la Casa de Salud de Valdecilla. 1968; 29(5 y 6).

M. de Armijo Valenzuela. Compendio de hidrología médica. Barcelona: Científico Médica; 1968.p 484

M. Armijo Valenzuela. Mecanismo de acción de las aguas minero medicinales. Boletín de la Sociedad Argentina de Estudios Termales. 1969; 8: 34-47.

M. Armijo. Antibioterapia en Estafilococias Penicilino Resistentes. Arch. Fac. Med. Madr. 1970; 17(1): 23-62.

M. Arevalo, A. Velasco, L.P. Rodríguez, M. Armijo. Efectos de L-Glutamina, Piridoxal y ácido gamma Aminobutírico sobre glicolisis y respiración cerebral. Arch. Inst. Farmacol. Exp.1970; 22(1y2): 47-62.

M. Armijo Valenzuela. Hidroterapia reumatológica. XII Curso sobre enfermedades reumáticas. Enseñanza de Reumatología. Facultad de Medicina. Madrid. 1970 18 de abril.

M. Armijo. Effects de l'eau radioactive. En: Actas del Congreso Internacional de Termalismo. Estoril. 1970

M. Armijo Valenzuela Terapéutica con psicofármacos. Colegio Oficial de Médicos. Murcia. 197010 de diciembre. 
M. Armijo Valenzuela. Hidroterapia y crenoterapia en las artropatías degenerativas. En: Simposio sobre artropatías degenerativas. Universidad de Madrid. Junio 1970.

J. M. Arévalo, A. Velasco, L. P. Rodríguez, M. Armijo. Efectos del glutamina, piridoxal y acido gamma aminobutírico sobre glicolisis y respiración cerebral. Arch. Inst. Farm. Exp1971; 23(1): 47-62,

M. Armijo, JM. Arévalo. Influencia del Agua Radiactiva sobre captación de oxígeno en tejidos cerebral y hepático. Arch. Inst. Farmacol. Exp.1971; 23(1 y 2): 103106.

M, Armijo, A. Velasco. Acción del Agua Radiactiva sobre el contenido de catecolaminas en tejido cerebral y aurícula de cobaya. Arch. Inst. Farmacol. Exp.1971; 23(1y 2): 107-108.

Manual Armijo Valenzuela. Drogas psicotropas y monoaminas biógenas. En: Homenaje al Profesor Benigno Lorenzo-Velázquez. Madrid: Oteo. 1971; p. 267274.

A. Velasco Martín, J. M. Arevalo Alonso and M. Armijo Valenzuela. Effect of Mecloqualone on the Oxigen and Glucose Uptake by Brain Tissue in vitro. Experientia.1972; 28(8): 934.

M. Armijo Valenzuela. Neurochimie et drogues tranquillisantes. Cahiers de Médicine (Europa Medica). 1972; 13(6): 447-449.

Armijo Valenzuela. Neurochemie und Tranquilizer. Münchener Medizinische Wochenschrift. 1972; 25: 12-14.

M. Armijo, L.P. Rodríguez, J. A. Rodríguez y J. San Martín. Acción del agua radiactiva sobre el crecimiento de cultivos de corazón embrionario. Arch. Fac. Med. Madr. 1972; 22(4): 185-189.

Manuel Armijo Valenzuela. Tratamiento hidrotermal das lumbalgias. O Médico. 1973, 68(1143); 154-159.

Armijo M. Hidroterapia en la artrosis de rodilla. Mesa redonda sobre artrosis de rodilla. Centro Nacional de Rehabilitación. Madrid. 1973, 19 mayo.

A. Velasco, J. M. Arévalo, J. San Martín y M. de Armijo. Efecto de algunos Psicofármacos sobre el consumo de oxigeno y glucosa de cerebro de rata in vitro. Rev Esp Fisiol. 1973; 29(1): 47-50.

J. L. Velasco, J. M. Arévalo, M. de Armijo y A. Velasco. Efecto del clorhidrato de piridoxina sobre el consumo de oxígeno y glucosa por algunos tejidos de rata in vitro. Rev Esp Fisiol. 1973; 29(1): 55-60.

Armijo M. Interés actual de las aguas mineromedicinales. En: Libro de actas de las primeras Jornadas de Calidad de las Aguas mineromedicinales. Madrid 1973.

Manuel Armijo Valenzuela. Uso y abuso de los antibióticos en estomatología. Arch. Fac. Med. Madr.1974; 25(3): 161-172.

Armijo Valenzuela M. Hidroterapia y crenoterapia de la gonartrosis. Acta Reumatol.1974; 1(2): 49. 
Armijo M, San Martín J, Armijo F. Acciones de la sauna sobre sujetos normales. Rehabilitación. 1974; 8(3): 559.

Manuel de Armijo Valenzuela. Tratamento hidrotermal das lumbalgias. . O Médico. 1974; 68.

Armijo M. Conssidération biologiques et Thérapeutiques des bains de vapeur en étuve thermale. En: Comptes-rendus du $1^{\circ}$ Congres Association Europeenne de Medecine Thermale. Merano. 1975; 57-64.

J. San Martín Bacaicoa, A. Roldán Álvarez, M.de Armijo Valenzuela. Résultats inmédiats de la kinébalnéotherapie en piscine thermale et d'eau ordinaire chaude dans le traitement des coxarthrosiques. En: Comptes-rendus du $1^{\circ}$ Congres Association Europeenne de Medecine Thermale. Merano. 1975;

J. San Martín, M. Armijo, F. Armijo. Modification de la formule leucocytaire chez les arthrosiques par les bains de vapeur. En: Comptes-rendus du $1^{\circ}$ Congres Association Europeenne de Medecine Thermale. Merano. 1975; 65-68.

F. Dorrego, C. Sunkel, M. Armijo. Liposolubilidad de ciertos esteres de la indometacina e intento de relación entre estructura química y actividad antiinflamatoria. En: Actas del $1^{\circ}$ Congreso Nacional de Ciencias Fisiológicas. Zaragoza. 1975, $25-28$ de junio. $\mathrm{p} 27$.

Armijo M. Psicofármacos. En: B. Lorenzo-Velázquez. Farmacología y su proyección a la clínica. 12a edición. Madrid; Editorial Oteo: 1975. p. 411-438.

Armijo M. Antiateromatosos. En: B. Lorenzo-Velázquez. Farmacología y su proyección a la clínica. 12a edición. Madrid; Editorial Oteo: 1975. p. 580-590.

Armijo M. Antibióticos. En: B. Lorenzo-Velázquez. Farmacología y su proyección a la clínica. 12ª edición. Madrid; Editorial Oteo: 1975. p. 876-891.

M. de Armijo Valenzuela y J. Borrachero del Campo. Criterios para valorar la efectividad de la cura termal en reumatología. Acta Reumatol.1975; 1: 123-128.

M. de Armijo Valenzuela. Hidroterapia y crenoterapia de la coxartrosis. Acta Reumatol. 1975; 1(5): 173-182.

Manuel de Armijo Valenzuela. Acciones sobre el organismo humano de las aplicaciones generales termobifásicas (sauna finlandesa). En: Instituto de España. Real Academia Nacional de Medicina. Madrid: 1975. P. 5-178.

M. de Armijo Valenzuela. Tratamiento hidrotermal de las lumbalgias. Acta Reumatol. 1976; 2: 109-116.

Borrachero, J; Armijo, M; Cotarelo. Estudio comparativo a doble ciego de un nuevo antiinflamatorio (ketoprofen con la fenilbutazona), en la poliartritis reumatoidea. En: Resumos II Congresso Portugues de Reumatologia, Porto. 1976.

Armijo M. Antiateromatosos. En: B. Lorenzo-Velázquez. Farmacología y su proyección a la clínica. 13a edición. Madrid; Editorial Oteo: 1976. p. 621-631.

Armijo M. Medicación hipouricemiante. Terapeutica antiúrica. Terapeutica antigotosa. En: B. Lorenzo-Velázquez. Farmacología y su proyección a la clínica. $13^{\mathrm{a}}$ edición. Madrid; Editorial Oteo: 1976. p. 747-756. 
Borrachero J.; Armijo M.; Alcalde A.; Muñoz R. Primeras experiencias con un nuevo analgésico antiinflamatorio (Eterilato) en Reumatología. $11^{\circ}$ Congreso Español de Reumatología. Oviedo. 1976, mayo.

Armijo M. Antibióticos. Penicilinas, Cefalosporinas y Acido fusídico. En: B. Lorenzo-Velázquez. Farmacología y su proyección a la clínica. $13^{\mathrm{a}}$ edición. Madrid; Editorial Oteo: 1976. p. 908-920.

Borrachero, J; Armijo, M; Vega, A; Muñoz, R. Primeras experiencias con un nuevo analgésico antiinflamatorio (Eterilato) en Reumatologia. En: Resumos $2^{\mathrm{a}}$ Congresso Portugues de Reumatologia. Porto. 1976, junio.

Manuel Armijo Valenzuela. La sauna en el tratamiento de las enfermedades reumáticas. Rev Reumatología. 1976. 1(2): 5.

F. Dorrego, C. Sunkel, M. Armijo. Relación entre actividad anti-inflamatoria y liposolubilidad de nuevos esteres fenólicos de la indometacina. Arch. Farmacol. Toxicol.1976; 2(1): 1-6.

Borrachero J.; Armijo M.; Alcalde A.; Iturriaga JM. Eterilato nuevo analgésico antiinflamatorio en Reumatología. $2^{\circ}$ Congreso Latino de Reumatología. Bucarest. 1976, septiembre.

M. Armijo Valenzuela, J. San Martín Bacaicoa. Sauna. Madrid: Oteo; 1976.

M. Piña, S. Alonso, P. Ortega y M. Armijo. Consideraciones acerca de la absorción, eliminación renal y efectos analgésicos y antiinflamatorios del eterilato, benorilato y acido acetilsalicílico. En: Libro de comunicaciones de la $3^{\text {a }}$ Reunión Nacional de la Asociación Española de Farmacólogos. Madrid. 1977, 21 - 23 Septiembre. p 99.

C. Sunkel, F. Cillero y M. Armijo. 2(p-Acetoamidofeniloxi)-Etil-Ocetoxibenzoato (Eterilato), Un Nuevo Antiinflamatorio derivado del Acido Acetilsalicílico. Síntesis y propiedades fisicoquímicas. En: Libro de comunicaciones de la $3^{a}$ Reunión Nacional de la Asociación Española de Farmacólogos. Madrid. 1977. 21 - 23 Septiembre. $p 120$.

Armijo M. La sauna en el tratamiento de las enfermedades reumáticas. Terapéutica. Buenos Aires. 1977

Armijo F, San Martín J, Armijo M. Representación grafica del análisis químico de las aguas minero-medicinales. An. bromatol. 1978; 30(1): 90-96.

Piña M, Alonso S, Ortega P, Armijo M. Consideraciones preliminares acerca de la absorción del eterilato, benorilato y ácido acetilsalicílico. Arch. Farmacol. Toxicol. 1978; 4(1): 120-122.

Armijo M. Hidroterapia y crenoterapia en el tratamiento de los reumatismos crónicos inflamatorios. Reumatol. Práctica. 1978; 2(2): 53-62.

Sunkel C,. Cillero F, Armijo M. (p-acetoamidofeniloxi)-etil-o-acetoxibenzoato (eterilato), Un nuevo antiinflamatorio derivado del acido acetilsalicílico síntesis y sus propiedades fisicoquímicas. Arch. Farmacol. Toxicol.1978; 4(1): 153-155. 
Piña M, Armijo M. Estudios de los efectos antiinflamatorios y analgésicos del eterilato, benorilato y ácido acetilsalicílico. Arch. Farmacol. Toxicol.1978; 4(1): 183-186.

Sunkel C, Cillero F, Armijo M, Piña M, Alonso S. Synthesis and Pharmacological Properties of Eterylate a New Derivative of Acetylsalicylic Acid. Arzneimttelforschung. Drug Res.1978; 28 (10): 1692-1694.

Rojo JM, Barasoain I, Portoles A, Armijo M. Variación de la actividad inmunosupresora por modificaciones estructurales en una serie de antiinflamatorios no esteroideos (esteres de la indometacina). Arch. Farmacol. Toxicol.1978; 4(3): 287292.

Alonso S, Armijo M, Piña M. Estudio experimental comparativo de la toxicidad aguda y tolerancia gástrica del eterilato, benorilato y ácido acetilsalicílico. Arch. Frmacol. Toxicol.1978; 4(3): 349-356.

Priego J.G, Piña M, Armijo M, Maroto L. Estudios de Farmacocinética y Biodisponibilidad del Etofibrato en la rata. En: Actas del I Congreso Hispano Francés de Biofarmacia y Farmacocinetica; Barcelona . 1979, 2 -6 Abril;

Alonso S, Armijo M, Ortega P. Acción del Etofibrato sobre la glucemia basal y tolerancia a la Glucosa, En: Actas del I Congreso Nacional de Ciencias Farmacéuticas. Barcelona 1979, 2-6 Abril.

Priego J.G, Piña M, Armijo M, Sunkel C. Maroto L. Acción del etofibrato, clofibrato y ácido nicotínico sobre el metabolismo lipídico en ratas normolipémicas. Efectos a corto plazo y modo de acción. Arch. Farmacol. Toxicol.1979; 5(1): 3-16.

Armijo M. Rehabilitación y balneoterapia en la tercera edad. $9^{\text {a }}$ Cong. Nac. de Geriatría y Gerontología. Santiago de Compostela. 1979, Junio.

Catalán RE, Aragonés MD, Martínez AM, Armijo M, Priego JG. Effects of Etofibrate, Clofibrate and Nicotinic Acid on the Cyclic Amp-Protein Kinasa System in Rats. Gen Pharmacol. 1979; 10(6), 455-458.

Armijo F, San Martín J, Armijo M. Contenido en sílice de algunas aguas minerales An. bromatol.1979; 31(3-4): p. 365-373.

Armijo M. Prólogo. En: Solsona F. Manual de terapéutica física natural. Zaragoza: Heraldo de Aragón; 1979

Armijo M. Antiateromatosos. En: B. Lorenzo-Velázquez. Farmacología y su proyección a la clínica. 14ª edición. Madrid; Editorial Oteo: 1979. p 588-594.

Armijo M. Medicación hipouricemiante. Terapéutica anti úrica. Terapéutica anti gotosa. En: B. Lorenzo-Velázquez. Farmacología y su proyección a la clínica. $14^{\mathrm{a}}$ edición. Madrid; Editorial Oteo: 1979. p. 691-698.

Armijo M. Antibióticos. Penicilinas, Cefalosporinas y Acido fusídico. En: B. Lorenzo-Velázquez. Farmacología y su proyección a la clínica. 14a edición. Madrid; Editorial Oteo: 1979. p. 837-847.

Catalán RE, Aragonés MD, Martínez AN, Armijo M, Piña M. Efect of Indometacin on the Cyclic Amp-Dependent Protein Kinase. Eur J Pharmacol. 1980; 63(2-3): 187-190. 
Armijo M. Hidroterapia y crenoterapia en el dolor de la cadera. Reumatol. Práct. 1980; 4(1): 39-42.

Ortega MP, Priego JG, Sunkel C, Armijo M. Efecto del eterilato sobre la agregación "in vitro" de plasma humano rico en plaquetas. Arch. Farmacol. Toxicol. 1980; 6(1): 31-40.

Armijo M, San Martín J. Hidroterapia y crenoterapia en el envejecimiento osteoarticular. Reumatol. Práctica. 1980; 4(4): 13-22.

Ortega MP, Sunkel C, Armijo M, Priego JG. Effects of etofibrate on platelet function: In vitro studies in human plasma. Tromb Res. 1980; 19: 409-416.

Armijo M. Hiperlipoproteinemias medicación selectiva. Publicaciones Científicas Alter. 1980; 19 (1): 2-14.

Armijo M. La crenoterapia en reumatología y su significación social. En: $3^{\text {a }}$ Reunión sobre prevención de los reumatismos. Liga Reumatológica Española. Murcia; 1980, 3 de octubre.

Armijo F., San Martín J., Armijo M. Contenido en Magnesio y relación calciomagnesio en algunas Aguas Mineromedicinales envasadas. An. bromatol. 1980; 32 (3): 215-222.

Armijo M. Contenido fluorado de las aguas minerales envasadas y sus posibles efectos sobre la salud. Anales de la Real Academia Nacional de Medicina. 1980; 97 (3): 429-462.

Armijo M. El termalismo español. Chambre Francaise de Commerce et d'Industrie Encuentro Hispano-Francés. 1981, 20 de Noviembre.

Armijo M. Peloterapia en las enfermedades reumáticas. Reumatol. Práctica. 1981; 5(4): 25-32 .

Borrachero J, Armijo M. Alcalde AP, Iturriaga JM. Eterilato en las enfermedades reumáticas. Reumatol. Práctica. 1981; 5(5): 29-42.

Armijo M, San Martín J. Armijo F. Consideraciones acerca de la mineralización predominante y relaciones iónicas de las aguas marinas y de las terrestres cloruradas sódicas- En: Actas del 18I Congreso Internacional de Talasoterapia. Las Palmas de Gran Canaria. 1981, 12-17 Febrero,

Armijo M, San Martín J. La talasoterapia como terapéutica de apoyo en el tratamiento de los síndromes de sobrecarga psíquica. En: Actas del 18 Congreso Internacional de Talasoterapia. Las Palmas de Gran Canaria 1981, 12-17 Febrero.

Armijo M, Alonso S, San Martín J. Estudio experimental de la acción del agua de Font Vella, sobre la curva ponderal y el consumo de alimento sólido y liquido. Acción del Agua de Font Vella sobre la diuresis en animales de experimentación. En: Actas del 17 Congreso Internacional. La Toja y Cuntis. 1981, 3- 8 de Mayo.

Statkov PR, Sunkel C, Fau M, Armijo M, Straumann D, Dorrego F. Selective Alpha Adrenergic Blocking Activity In a Series of New Prazosin Derivatives. En Actas Eighth International Congress of Pharmacology. 1981, July 19-24.

Armijo M. La cura balnearia en el tratamiento del síndrome toxico. Anales de la Real Academia Nacional de Medicina. 1981; 98(4): 587-591. Spanish 
Armijo M. La cura balnearia en el envejecimiento condroarticular. Anales de la Real Academia Nacional de Medicina. 1981; 98(4): 603-626.

Maroto ML, Armijo M, Priego JG. Efectos in vitro del etofibrato sobre el metabolismo lipídico. En: Actas del $4^{\circ}$ Congreso Nacional de Química. Química Sanitaria. Madrid 1981, 26, 27, y 28 de Octubre.

Ortega MP, Armijo M, Lázaro A, Priego JG, Sunkel C. Distribución del eterilato-14c en la rata. En: Actas del $4^{\circ}$ Congreso Nacional de Química. Química Sanitaria. Madrid 1981, 26, 27, y 28 de Octubre.

Maroto ML, Armijo M, Sunkel C, Piña M, Priego JG. Perfil farmacológico de un nuevo derivado del acido nicotínico (ned-124). En: Actas del $4^{\circ}$ Congreso Nacional de Química. Química Sanitaria. Madrid 1981, 26, 27, y 28 de Octubre.

Armijo M. Una terapéutica de apoyo en el tratamiento del síndrome de sobrecarga psíquica. Pulso Periódico. 1981; 14 (13).

Armijo M. Estudio comparativo do Etofibrato com outros agentes hipolipidérmicos. Estudo da acçao do Etofibrato sobre a funçao plaquetária. En Actas de las Segundas Jornadas Internacionais de Aterosclarose. Serviços de Medicina II Dosh.U.C.1981, 3-4-5. dezembro.

Armijo M. Dureza y relación calcio-magnesio de las "aguas de mesa" y su posible influencia sobre las cardiopatías isquémicas. Anales de la Real Academia Nacional de Medicina. XVII Sesión Científica. 1982; 99(3) 415-436.

Armijo M, San Martín J. Hidroterapia y crenoterapia (Gonartrosis). Rheuma. 1982; 1: 73-78.

Armijo M, San Martín J. Hidroterapia y Crenoterapia en la coxartrosis. Rheuma. 1982; 2: 63-69.

Armijo M, San Martín J. Hidroterapia y Crenoterapia en las lumbartrosis. Rheuma. 1982; 3: 58-64.

Ortega MP, Sunkel C, Armijo M, Priego JG. Effect of Eterylate on Human Platelet Responsive-Ness es Vivo: A Study in Human Volunteers. En: Actas de Seventh Internacional Congress on Trombosis. Valencia Spain; 1982, October 13-16.

San Martín J, Armijo M. Hydrotherapie dans des troubles fonctionelles en rehumatologie. En Actas del Congreso Internacional do Termalismo Médico. Internacional Society of Medical Hidrology and Climatology. Ponta Delgada, Açores, Portugal. 1982, 2-6 Maio.

Armijo M, San Martín J. La thalassotherapie et le traitement du surmenage professionnel. En: Actas do Congresso Internacional do Termalismo Médico. Internacional Society of Medical Hidrology and Climatology. Ponta Delgada, Açores, Portugal.1982 2-6 Maio. p 121-128.

Armijo M, San Martín J. Relations ioniques entre les eaux chlorurees terrestres et marines. En: Actas do Congresso Internacional do Termalismo Médico. Internacional Society of Medical Hidrology and Climatology. Ponta Delgada, Açores, Portugal 1982, 2-6 Maio. 
Armijo M, San Martín J. Hidroterapia y crenoterapia en el tratamiento de la inflamación crónica. Rheuma.1982; 1(mayo). 82-90.

Armijo M. Consideración actual de la cura balnearia. En: Actas de las Primeras jornadas de medicina balneoterápica de Esukadi en Zestoa. 1982, 8 de junio.

Armijo M. Significación biológica y terapéutica de los iones atmosféricos. Anales de la Real Academia Nacional de Medicina. 1983; 100(4); 635-668.

San Martín J, Armijo M, Armijo F. Efectos de los baños de sauna sobre el equilibrio catiónico en sudor, plasma y orina se sujetos normales. Rehabilitación. 1983; 17 (2): 165-174.

Armijo M. Balneoterapia en las enfermedades reumáticas. $5^{\circ}$ Simposio Internacional de Reumatología de Madrid. Madrid. 1983, 22-23 de abril. En: Reumatol. Práctica.1983; Extra: 39-48.

Armijo M. Cura balnearia e identidad biopsicológica. Anales de la Real Academia Nacional de Medicina. XI Sesión Científica. 1983; 100 (4): 333- 352.

Armijo M, Priego JG. O etofibrato como agente hipolipidemiante. Revista Portuguesa de Clinica e Terapeutica. 1983; 8(1).

Priego JG, Maroto ML, Ortega MP, Armijo M. Niveles en suero de ácido salicílico y paracetamol tras administración oral de eterilato. Arch. Farmacol. Toxicol. 1983; 9(1): 39-46.

Alonso S, Ortega MP, Armijo M. Acción del eterilato, benorilato y acido aceltisalicílico sobre la glucemia en ratas normales y diabetizadas experimentalmente. Arch. Farmacol. Toxicol. 1983; 9(2): 183-190.

Armijo M, San Martín J. La cura hidrotermal en las algias reumáticas. Rheuma.1983; 7(1): 56-60.

Priego JG, Ortega MP, Armijo M. Acçoes do etofibrato sobre a funçao plaquetaria Revista Portuguesa de clinica e terapeutica. 1983; 8 (5)

Armijo M. Incontri dedicati al moderni orientamenti della medicina termale e della climatologia medica. Universita degli Studi di Milano. Cattedra di Idrologia e Climatologia Medica. Gran Canarie (Spagna). 1983, 5 al 12 Dicembre.

Armijo M. Consideraciones sobre la cura Balnearia en su pasado, presente y futuro La balneoterapia en la medicina actual. En Actas de las Primeras Jornades de Medicina i Balnearis als Pa sos Catalans. Caldes de Montbui. 1984. 24 i 25 de Març

Armijo M, San Martín J. Hidroterapia y Crenoterapia. Artritis Reumatoidea. Rheuma. 1984; 8 (1): 55-60

Armijo M. Giornate Mondiale Del Termalismo. Convegno Onternazionale Di Studio. $4^{\circ}$ Conferenza Mondiale OMTH. XVI Symposium Internazionale . AITI. III Congreso Internazionale AEMTB. 1984, 24-25-26-27 Maggio

Armijo M. Consideración actual de la cura balnearia. En: Actas de las Primeras jornadas de medicina balneoterápica de Euskadi en Zestoa. 1984 7-9 de junio. 
Armijo M. Situación actual de la cura Balnearia. En: Actas de las $2^{\text {a }}$ Xornadas Galegas de Termalismo. Consellería de Sanidade e Consumo. Carballiño (Ourense). 1984, 19-20-21 Outono

Armijo M, Bartoletti CA, Fazzi G, Fuentes A, Gualtierotti R, San Martín J, Tonoli J. Nuovi aspetti della Talassoterapia promossa dalla Socita Mediterranea di Talassologia e Talassoterapia. En: Tavola Rotonda: II Giornate di Studio di Talassologia e Talassoterapia. Universita degli Studi di Milano. 1984, 3-10 Dicembre.

Armijo M, Der Mitglieder der Deutschen Gesellschaft für /Physikalische Medizin und Rehabilitation. Publikations Verzeichnis. Herausgegeben und bearbeitet von Klaus L. Schmidt. 1984.

Armijo M. Hidroterapia y Crenoterapia. Curso de Educación Continuada y Reciclaje Reumatológico. Universidad Complutense de Madrid, Fac. Medicina, Hospital Clínico. Servicio de Reumatología. 1984.

Armijo M, San Martín J. La Salud por las aguas termales. Madrid: Edaf; 1984. págs 120

San Martín J, Armijo M. Hidro y crenocinesiterapia en los reumatismos yuxtaarticulares. Rheuma. 1985; 22: 52-58

Armijo M. Sosiedade Espanhola de Hidrología. V.Centenario 1485-1985. Colóquio Termal das Caldas da Rainha. Encontro Luso-Espanhol de Hidrología Médica. 1985, 6-9 de Junio.

Armijo M. La enseñanza por objetivos. $2^{\circ}$. Seminario sobre Enseñanza de la Medicina. Instituto de Ciencias de la Educación. 1985, 9 de diciembre.

Armijo M. Curso Básico de Hidrología. Carballiño (Ourense). 1985, 28, 29, 30 Marzo.

Armijo M. Historia del termalismo en España. Publ. do Inst. Hidrol. da Univ. Coimbra. 1985; 28:73-83.

Armijo M, San Martín J. Hidroterapia. Publicación en fascículos coleccionables Conceptos y evolución histórica de la hidroterapia. Bol. Soc. Esp. Hidrol. Med.1986; 1 (1): 3-12.

Armijo M. Hidroterapia y Crenoterapia. Curso de Educación Continuada y Reciclaje Reumatológico. 1986, Octubre-Diciembre.

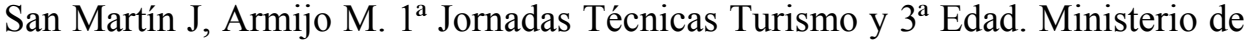
Transportes, Turismo y Comunicaciones. 1986, 7, 8, 9 Octubre.

Armijo M. Sesión necrológica en memoria del Excmo. Sr. D. Benigno Lorenzo Velázquez. Anales de la Real Academia Nacional de Medicina. 1986;. 103(1): 2537.

Armijo M. Augas "Vieiros De Saude". II Curso Básic de Hidrología Médica. O Carballiño. 1986. 1-2-3-4 de Mayo.

Armijo M, San Martín J. Hidroterapia. Publicación en fascículos coleccionables El agua agente hidroterápico. Bol. Soc. Esp. Hidrol. Med.1986; 1(2): 13-24.

Armijo M. Curas termales en el envejecimiento condro articular. Bol. Soc. Esp. Hidrol. Med.1986;1(2): 69-74. 
Armijo M, San Martín J. Hidroterapia. Publicación en fascículos coleccionables Consideraciones hidrotérmicas. Bol. Soc. Esp. Hidrol. Med.1986; 1(3): 25-36.

Armijo M, San Martín J. Hidroterapia. Publicación en fascículos coleccionables Acciones inespecíficas de los tratamientos hidroterápicos. Bol. Soc. Esp. Hidrol. Med.1987; 2(1): 37-48.

Armijo M, San Martín J. Hidroterapia. Publicación en fascículos coleccionables Instalaciones hidroterápicas. Bol. Soc. Esp. Hidrol. Med.1987; 2(2): 49-60.

Armijo M. Laudatio en Toma de Posesión como Académico. Correspondiente Honorario a la Excma. Sra. Da Amparo Pérez Carnicero. Anales de la Real Academia Nacional de Medicina. 1987; 104(4) 429-436.

Armijo M. Contestación al Discurso Toma de .Posesión. Prof. Sánchez García. Anales de la Real Academia Nacional de Medicina. 1987; 104(4).

Armijo M, Armijo F. Influencia de la dureza y de la relación Calcio/Magnesio de las aguas de bebida sobre las Hiperlipidemias y procesos vaso oclusivos. Bol. Soc. Esp. Hidrol. Med.1987; 2(2): 83-88.

Armijo M. Crenoterapia das afeçoes com indição crenoterápica. Bases da crenoterapia das efecções digestivas. Caldelas- $4^{a}$ Sessăo. Facultad de Medicina de Coimbra. 1987, 9-10 Maio.

Armijo M. Termalismo en la actualidad, diversas escuelas, aceptación posibilidades de desarrollo. $3^{\circ}$ Curso Básico de Hidrología Médica. O Caballiño. 1987, 1617 de Mayo.

Armijo M. Aplicaciones actuales del termalismo en afecciones no reumáticas. Seminario de Hidrología Médica. Asociación Balnearia de Cataluña. La Garriga. 1987, 6 y 7 de marzo.

Armijo M, San Martín J. Hidroterapia. Publicación en fascículos coleccionables Clasificación de las Técnicas hidroterápicas. Bol. Soc. Esp. Hidrol. Med.1987; 2 (3): 61-72.

San Martín J, Armijo M. Balneoterapia: Sus posibilidades en el dolor crónico de espalda En: $4^{\circ}$ Curso Internacional del Estudio y Tratamiento del Dolor. Facultad de Medicina. Hospital General de Murcia. Murcia. 1988, 2930 de Enero

Armijo M. Rehabilitación en Reumatología: métodos tradicionales y nuevas aportaciones. Del Balneario al Láser. Institutito Poal de Reumatología. Barcelona 1988 .

Armijo M. La cura balnearia en el tratamiento de procesos neuróticos e infraneuróticos. Bol. Soc. Esp. Hidrol. Med.1988; 3(1): 29-34.

Armijo M, San Martín J. Hidroterapia. Publicación en fascículos coleccionables Baños generales, regionales y locales. Bol. Soc. Esp. Hidrol. Med.1988; 3(1): 7384.

Armijo M. Interés actual de las Aguas envasadas. En: Xunta de Galicia. Conselleria de Sanidade (eds.). El termalismo en la década de los ochenta. Pontevedra.1988. p.159-168. 
Armijo M. Indicaciones actuales de las curas hidrotermales. En: Xunta de Galicia. Conselleria de Sanidade (eds.). El termalismo en la década de los ochenta. Pontevedra.1988. p.209-221.

Armijo M. Crenoterapia de las afecciones respiratorias. En: Xunta de Galicia. Conselleria de Sanidade (eds.). El termalismo en la década de los ochenta. Pontevedra.1988. p.255-263.

Armijo M. La cura termal en las afeciones osteo-articulares de la tercera edad. En: Xunta de Galicia. Conselleria de Sanidade (eds.). El termalismo en la década de los ochenta. Ponteve-dra.1988. p.327-339.

Armijo M. Situación actual de la cura balnearia. En: Xunta de Galicia. Conselleria de Sanidade (eds.). El termalismo en la década de los ochenta. Pontevedra.1988. p.429-440.

Armijo M, San Martín J. Hidroterapia. Publicación en fascículos coleccionables Baños generales, regionales y locales (II). Bol. Soc. Esp. Hidrol. Med.1988; 3(2): 85-96.

Armijo M. Las aguas minero medicinales, su acción sobre el organismo humano. En: $1^{\circ}$ Encuentro monográficos sobre problemas del agua. El agua de bebida y la salud: El agua como alimento. El agua como medicamento Madrid. 1988, 20-21-22 abril.

Armijo M. Mecanismos de Acción de las Aguas Minero-Medicinales. Cura Balnearia, Concepto y Clasificación. En: $4^{\circ}$ Curso Básico de Hidrología Médica. O Carballiño.1988, 7-28-29 de Mayo.

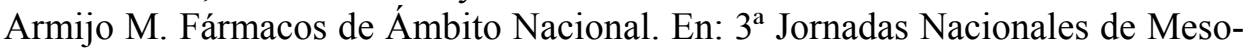
terapia. Barcelona. 1988, 3,4 y 5 de junio.

Armijo M, San Martín J. Hidroterapia. Publicación en fascículos coleccionables Baños generales, regionales y locales (III). Bol. Soc. Esp. Hidrol. Med.1988; 3 (3): 97-108.

Armijo M. Interés Terapéutico de las Aguas Minerales Envasadas. En: Congreso Latino de Hidrología Médica. Asociación Balnearia de Cataluña. Balneario Vichi Catalán. 1988, 20, 21 y 22 de octubre.

Armijo M. Interés terapéutico de las aguas minerales envasadas. Bol. Soc. Esp. Hidrol. Med.1988; 3(3): 133-134.

Armijo M. El termalismo en España. Bol. Soc. Esp. Hidrol. Med.1988; 3(3): 141-142.

Armijo M. La relación médico enfermo en las curas balnearias. Bol. Soc. Esp. Hidrol. Med.1989; 4(1): 9-12.

Armijo M, San Martín J. Hidroterapia. Publicación en fascículos coleccionables Cura de Kneipp o kneipterapia. Bol. Soc. Esp. Hidrol. Med.1989; 4(1): 109-120.

Armijo M. Depresiones en la Tercera Edad y cura Balnearia. Bol. Soc. Esp. Hidrol. Med.1989; 4(2): 81-85. 
Armijo M, San Martín J. Hidroterapia. Publicación en fascículos coleccionables. Hidrocinesiterapia e Hidrogimnasia. Bol. Soc. Esp. Hidrol. Med.1989; 4(2): 121132.

Armijo M. Rehabilitación, Hidroterapia, Balneoterapia. En: 26 Jornada de la Sociedad Castellano-Leonesa de Rehabilitación. Palencia. 1989, 6 de Mayo.

Armijo M. Balneario Las Caldas de Partovia. Bol. Soc. Esp. Hidrol. Med.1989; 4(3): 149-153.

Armijo M. Spas. Consideraciones acerca de las Piscinas Terapeuticas. En: Salón Internacional del Agua. Zaragoza 1989, 6 de junio.

Armijo M. La Balneoterapia en la Medicina actual. En: I Jornadas sobre el futuro del termalismo. Universidad Nacional de Educación a Distancia. Centro Asociado de Calatayud. 1989, 28, 29 y 30 de septiembre.

Armijo M. Sesión Necrológica en Memoria del Académico de Número Excmo. Sr. D. Félix Sanz Sánchez. Anales de la Real Academia Nacional de Medicina. 1989; 106(3); 477- 486.

San Martín J, Armijo F, Armijo M. Composición de las aguas madres preparadas a partir de agua marina y de agua minero medicinal. Bol. Soc. Esp. Hidrol. Med.1990; 5(1): 149-153.

Armijo M, San Martín J. Hidroterapia. Publicación en fascículos coleccionables. Hidrocinesiterapia e Hidrogimnasia (II). Bol. Soc. Esp. Hidrol. Med.1990; 5(1): 133-144.

Armijo M. Evolución del termalismo en España. $6^{\circ}$ International Rehabilitation Medicine Association. World Congress. Madrid. 1990, 17-22 June. p. 235

Armijo M, San Martín J. Hidroterapia. Publicación en fascículos coleccionables. Afecciones Neurológicas. Bol. Soc. Esp. Hidrol. Med.1990 5(2): 145-156.

Armijo M. Evolución del termalismo en España. Bol. Soc. Esp. Hidrol. Med.1990; 5(3): 149-153.

Armijo M. Estrés y Kneippterapia. Anales de la Real Academia Nacional de Medicina 1990; 107(3): 413-427.

Armijo M, San Martín J. Hidroterapia. Publicación en fascículos coleccionables. La natación en hidrología. Bol. Soc. Esp. Hidrol. Med.1990 5(3): 157-168.

Armijo M. Antecedentes históricos y evolución de la especialidad. En: Organización Médica Colegial. Hidrología. Madrid: Consejo General de Colegios Médicos de España; 1990. p. 1-15.

Armijo M, San Martín J. La formación continuada en la especialidad. En: Organización Médica Colegial. Hidrología. Madrid: Consejo General de Colegios Médicos de España; 1990. p. 59-70.

San Martín J, Armijo M. La formación de especialistas en las comunidades europeas. En: Organización Médica Colegial. Hidrología. Madrid: Consejo General de Colegios Médicos de España; 1990. p.73-87.

Armijo M, San Martín J. Hidroterapia. Publicación en fascículos coleccionables. La natación en hidrología. Bol. Soc. Esp. Hidrol. Med.1991 6 (1): 169-179. 
Armijo M. Aguas minerales y mineromedicinales: Mecanismos básicos de acción. En actas de las Jornadas sobre Aguas Subterráneas y su Geología en Andalucía: Sevilla, Instituto Tecnológico Geominero de España. Junta de Andalucía, Dirección General de Industria, Energía y Minas. 1991, 9 y 10 de octubre. p. 8-17.

Armijo M. Reumatismos degenerativos y curas hidrotermales. Bol. Soc. Esp. Hidrol. Med.1991; 6 (2): 69-78.

Armijo M. Curas balnearias en las depresiones de la tercera edad. Anales de la Real Academia Nacional de Medicina. 1991; 108(3): 669-678.

San Martín J, Armijo F, Armijo M. Composición de las aguas madres preparadas a partir de agua marina y de agua minero medicinal .En: Actualidades en Medicina Física y Rehabilitación. Congreso Europeo de Madrid. Luis Pablo Rodríguez. SEPRESA. Madrid. 1991. p 231-233.

Armijo M. La Balneación en el arte pictórico. Ateneo de Zaragoza. Sesión Inaugural del curso 1991-1992. 1991, noviembre.

Rojas E, Armijo M. La cura balnearia en los síndromes asténicos. Bol. Soc. Esp. Hidrol. Med.1993; 8(2): 67-73.

Armijo M. Aguas minerales y mineromedicinales: mecanismos básicos de acción. Bol. Soc. Esp. Hidrol. Med.1993; 8(2): 96-100.

Armijo M. El sueño, los sueños y las curas balnearias. Instituto de España. Real Academia Nacional de Medicina. Madrid 1993; 3-24.

Armijo M. Mecanismos de acción de las aguas mineromedicinales en relación con la rehabilitación. Bol. Soc. Esp. Hidrol. Med.1993; 8(3): 135-143.

Armijo M. Aguas mineromedicinales. $10^{\circ}$ Conferencia sobre Hidrología general y aplicada. $10^{\circ}$ Salón Internacional del agua. Zaragoza. 1993, 17-19 de febrero.

Armijo M. Cansancio de la vida. Bol. Soc. Esp. Hidrol. Med.1994; 9(2): 69-74.

Armijo M, San Martín J. Curas balnearias y Climáticas. Madrid: Editorial Complutense; 1994.

Armijo M, Rodríguez LP. Medicinas alternativas. Academia Nacional de Medicina.1996; 113(2); 241-260.

Armijo M. Presentación del profesor Francisco López Timoneda. Anales de la Real Academia Nacional de Medicina.1996; 113(3); 545-547.

Armijo M. Necrológica en memoria del Excmo. Sr. D. José Pérez Llorca. Anales de la Real Academia Nacional de Medicina.1996; 113(4); 951-961.

Armijo M. Médicos hidrólogos ilustres: homenaje al Dr. Anastasio García López, en el centenario de su fallecimiento. Bol. Soc. Esp. Hidrol. Med. 1997; 12(3): 153-156.

Armijo M. Medicina Naturista - curas balnearias. Anales de la Real Academia Nacional de Medicina. 1998; 115(1): 221-257.

Armijo M. Lucubraciones acerca de las curas balnearias en el sentimiento de tristeza. 1999; 116(2): 279-294.

Armijo M. Curas balnearias. Asistencia sanitaria y salud pública Anales de la Real Academia Nacional de Medicina.2000; 117(2): 283-302. 
Armijo M. Interés sanitario de las aguas de bebida envasadas Anales de la Real Academia Nacional de Medicina. 2001; 118(3): 459-474.

Armijo M. Interés sanitario de las aguas carbónicas carbogaseosas o acídulas Anales de la Real Academia Nacional de Medicina. 2002; 119(1): 175-197.

Armijo M. Envejecimiento, cansancio de la vida. Curas balnearias Anales de la Real Academia Nacional de Medicina. 2003; 120(2): 355-373.

Armijo M. Consideraciones en torno a las curas balnearias Anales de la Real Academia Nacional de Medicina. 2004; 121(3): 391-401.

Armijo M. Interés terapéutico de las curas balnearias. 2005; 122(3): 433- 450.

Armijo M. Curas balnearias en cuadros depresivos y depresiones encubiertas Anales de la Real Academia Nacional de Medicina. 2006; 123(3): 673-688.

Armijo M. Curas Balnearias y estados de salud. Anales de la Real Academia Nacional de Medicina. 2007; 124(2): 381-396. 